\title{
A survey of automatic control methods for liquid-propellant rocket engines
}

\author{
Sergio Pérez-Roca ${ }^{\mathrm{a}, \mathrm{c}, *}$, Julien Marzat ${ }^{\mathrm{a}}$, Hélène Piet-Lahanier ${ }^{\mathrm{a}}$, Nicolas Langlois ${ }^{\mathrm{b}}$, François Farago $^{\mathrm{c}}$, Marco Galeotta $^{\mathrm{c}}$, \\ Serge Le Gonidec ${ }^{\mathrm{d}}$ \\ ${ }^{a}$ DTIS, ONERA, Université Paris-Saclay, Chemin de la Huniere, 91123 Palaiseau, France \\ ${ }^{b}$ Normandie Université, UNIROUEN, ESIGELEC, IRSEEM, Rouen, France \\ ${ }^{c}$ CNES - Direction des Lanceurs, 52 Rue Jacques Hillairet, 75612 Paris, France \\ ${ }^{d}$ ArianeGroup SAS, Forêt de Vernon, 27208 Vernon, France
}

\begin{abstract}
The main purpose of this survey paper is to review the field of convergence between the liquid-propellant rocketpropulsion and automatic-control disciplines. A comprehensive collection of academic works and some industrial developments are summarised and discussed, making the link to the current context of launcher reusability. The main control problem in liquid-propellant rocket engines (LPRE), the target of this survey, generally consists in tracking set-points in combustion-chamber pressure and mixture ratio, their main operating quantities. This goal is attained via the adjustment of flow-control valves while complying with operating constraints. Each aspect of control systems, ranging from modelling to the actual control techniques, is reviewed and subsequently related to the rest of aspects. The comparison of the different approaches points to the general use of linearised models about concrete operating points for deriving steady-state controllers, which in most cases are of PID type. Other more sophisticated approaches present in the literature, incorporating some nonlinear, hybrid or robust techniques, improve certain aspects of performance and robustness. Nevertheless, no fully nonlinear or hybrid frameworks, which may allow the control of a wider throttling domain, have been published. In addition, control during the thermally and structurally demanding transient phases is usually in open loop, and hence with low correction margins. This sort of control enhancements, probably together with more sophisticated monitoring architectures, would serve to extend the life of LPRE, a significant factor in their reusability. Therefore, this survey intends to draw a path for the future control design trends which will certainly be more suitable for reusable LPRE.
\end{abstract}

Keywords: Liquid-propellant rocket engines, automatic control, thermodynamic systems, reusability, modelling, review.

\section{Introduction}

The automatic control of liquid-propellant rocket propulsion systems is a specific field that presents multiple goals and constraints and that in practical terms tends to be simplified for adapting to the restrictive real space-engineering scenarios.

Even if the first reference reviewed dates from the 1950 s, a relatively low number of publications covering both disciplines at the same time can be found in the literature. This fact might stem from intentional confidentiality strategies by companies and agencies,

\footnotetext{
${ }^{*}$ Corresponding author.

Phone: +33180386657

Email address: sergio.perez_roca@onera.fr (Sergio Pérez-Roca)
}

since rocket engines are complex two-sided technological assets (with military and civil uses), generally needing wide technical know-how. But it could also mean that this bi-disciplinary topic has not been extensively tackled by the research community. Hence, the expected benefits of this article are two-fold. On the one hand, it is intended to provide the designers of liquidpropellant rocket engines (LPRE) with possibilities to enhance their control systems, seeing the current evolving context of reusable launchers. On the other hand, the automatic-control community may find challenging cutting-edge applications of their control techniques. Therefore, background introductions on each field are provided throughout the article.

The automatic control of any type of system generally pursues that the system behaves as expected, according to some predefined references. In the case of LPRE, 


\begin{tabular}{|c|c|c|c|}
\hline \multicolumn{4}{|c|}{ Nomenclature } \\
\hline$e$ & Subscript for nozzle exit & HMS & Health Monitoring System \\
\hline$t$ & Subscript for throat & HPT & High-Pressure Turbine \\
\hline$\dot{m}$ & Mass flow $[k g / s]$ & ICS & Intelligent Control System \\
\hline$\gamma$ & Specific heat ratio [-] & JAXA & Japanese Aerospace Exploration Agency \\
\hline$\omega$ & Rotational speed $[\mathrm{rad} / \mathrm{s}]$ & $\mathrm{LCH} 4$ & Liquid Methane \\
\hline$\Phi$ & Heat transfer $[W]$ & LEC & Life-Extending Control \\
\hline$\rho$ & Density $\left[\mathrm{kg} / \mathrm{m}^{3}\right]$ & LFT & Linear Fractional Transformation \\
\hline$c$ & Subscript for cavity/combustion/chamber & LH2 & Liquid Hydrogen \\
\hline$A$ & Area $\left[m^{2}\right]$ & LMI & Linear Matrix Inequality \\
\hline \multicolumn{2}{|c|}{$A, B, C, D$ Standard state-space matrices } & LOX & Liquid Oxygen \\
\hline$C^{*}$ & Characteristic exhaust speed $[\mathrm{m} / \mathrm{s}]$ & LPRE & Liquid-Propellant Rocket Engine \\
\hline$F$ & Thrust $[N]$ & LPV & Linear Parameter-Varying \\
\hline$g_{0}$ & Standard gravity acceleration $\left[\mathrm{m} / \mathrm{s}^{2}\right]$ & \multirow{2}{*}{\multicolumn{2}{|c|}{$\begin{array}{l}\text { LQG/LTR Linear Quadratic Gaussian/Loop Transfer- } \\
\text { function Recovery }\end{array}$}} \\
\hline$H$ & Enthalpy $[J / k g]$ & & \\
\hline$I_{s p}$ & Specific impulse $[s]$ & LQR & Linear-quadratic regulator \\
\hline$I_{T P}$ & Shaft inertia $\left[\mathrm{kg} \cdot \mathrm{m}^{2} / \mathrm{s}\right]$ & LS & Least Squares \\
\hline$k_{\text {res }}$ & Component's resistance coefficient $[1 /(\mathrm{kgm})]$ & LVDT & Linear Variable Differential Transformer \\
\hline$L$ & Length $[m] / /$ Liquid & MBFD & Model-based fault detection \\
\hline$M$ & Molecular weight $[\mathrm{kg} / \mathrm{mol}]$ & MFV & Main Fuel Valve \\
\hline$M R$ & Mixture ratio [-] & MIMO & Multi-Input Multi-Output \\
\hline$p$ & Pressure $[\mathrm{Pa}, \mathrm{bar}]$ & MOV & Main Oxidiser Valve \\
\hline$R$ & Gas constant $[\mathrm{J} / \mathrm{kgK}]$ & MPC & Model Predictive Control \\
\hline$s$ & Laplace variable & NASA & National Aeronautics and Space Administration \\
\hline$T$ & Temperature $[K]$ & NLP & Nonlinear Programming \\
\hline$t$ & Time $[s]$ & $\mathrm{O}, \mathrm{ox}$ & Oxidiser \\
\hline$T q$ & Torque $[\mathrm{Nm}]$ & ODE & Ordinary Differential Equations \\
\hline$u$ & Control input $[\mathrm{m} / \mathrm{s}]$ & OL & Open Loop \\
\hline$V$ & Volume $\left[m^{3}\right]$ & OPOV & Oxidiser Preburner Oxidiser Valve \\
\hline$x$ & State vector & PI & Proportional-Integrator Controller \\
\hline$y$ & Output vector & PID & Proportional-Integrator-Derivative Controller \\
\hline$H_{\infty}$ & $\mathrm{H}$ infinity norm for robust control & PLC & Programmable Logic Controller \\
\hline ACC & Active Combustion Control & PRBS & Pseudorandom Binary Sequence \\
\hline $\mathrm{CC}, \mathrm{C}$ & Combustion chamber & PWM & Pulse-Width Modulation \\
\hline CL & Closed Loop & $\mathrm{RC}$ & Reconfigurable Control \\
\hline CNES & Centre National d'Études Spatiales & RML & Recursive Maximum Likelihood \\
\hline DF & Describing functions & RREC & Robust Rocket Engine Concept \\
\hline ESA & European Space Agency & RTD & Resistance Temperature Devices \\
\hline $\mathrm{F}, \mathrm{fu}$ & Fuel & RVDT & Rotary Variable Differential Transformer \\
\hline FDD & Fault Detection and Diagnosis & SISO & Single-Input Single-Output \\
\hline FDI & Fault Detection and Isolation & SQP & Sequential Quadratic Programming \\
\hline FPOV & Fuel Preburner Oxidiser Valve & SSME & Space Shuttle Main Engine \\
\hline FTCS & Fault-tolerant Control Systems & $\mathrm{TCV}$ & Thrust Control Valve \\
\hline $\mathrm{GG}, \mathrm{G}$ & Gas generator & $\mathrm{TP}$ & Turbopump \\
\hline HIL & Hardware in the Loop & TVC & Thrust-Vector Control \\
\hline
\end{tabular}


the system studied in this paper, these references generally correspond to the two variables defining its operating envelope: combustion-chamber pressure (related to thrust) and mixture ratio (oxidiser to fuel ratio), which are usually controlled via adjustable valves. In order to explain the physical meaning of these variables and components, an introduction to the working principles of rocket engines seems necessary.

\subsection{Rocket engine generalities}

Chemical rocket engines, mainly used to propel launch vehicles and spacecraft, can be classified in the first place according to the state in which the chemical propellant is stored: i.e. solid-propellant, liquidpropellant and hybrid (mixture of both) engines. Indeed, propellants nature determines to a great extent the conception of these systems. The chemical compounds furnished to the rocket engine undergo several thermodynamic transformations throughout their flow through the engine lines and components. The main phenomena are their combustion and expansion, the phenomena that ultimately produce thrust, the raison d'être of engines. As mentioned earlier, in this paper only LPRE are covered.

LPRE consist in one of the most complex propulsion systems for many reasons. Very high thrust forces $(F)$ can be generated (until the order of $10 M N$ ), corresponding to power amounts of $3-4 G W[1]$. Extreme temperature $(T)$ differences are observed between cryogenic tanks, which can be at $20 K$ for liquid hydrogen; and combustion chamber core, which can surpass the $3500 K$. These quantities are related to elevated combustion pressures $\left(p_{c}\right)$ too, in excess of 200bar in the most powerful engines. Fig. 1 depicts two examples of LPRE, the European Vulcain 2 and the US-American $R S-68$. The basic static equations relating these main LPRE performance quantities are the following, in their ideal form:

$$
\begin{gathered}
\dot{m}_{c}=\frac{p_{c} A_{t}}{C^{*}}=\frac{p_{c} A_{t}}{\sqrt{T_{c}}} \sqrt{\frac{\gamma}{R}\left(\frac{\gamma+1}{2}\right)^{-\frac{\gamma+1}{\gamma-1}}} \\
I_{s p}=\frac{1}{g_{0}} \sqrt{R T_{c} \frac{2 \gamma}{\gamma-1}\left(1-\left(\frac{p_{e}}{p_{c}}\right)^{\frac{\gamma-1}{\gamma}}\right)} \\
F=\dot{m}_{c} I_{s p} g_{0}=C_{F} p_{c} A_{t}
\end{gathered}
$$

where $\dot{m}$ is the mass flow rate, $A_{t}$ is the throat area, $C^{*}$ is the characteristic exhaust speed, $T_{c}$ is the combustion temperature, $\gamma$ is the specific heat ratio, $R$ is the gas constant of the mixture, $g_{0}$ is the standard gravity acceleration, $p_{e}$ is the exhaust pressure, $C_{F}$ is the thrust coefficient and $I_{s p}$ is the specific impulse. The latter is the ratio of thrust to ejected mass flow, and hence represents the efficiency of the engine. Mixture ratio $(M R)$, defined as the ratio between oxidiser and fuel mass flows, has an influence on the previous formulae via $T_{c}$ and thermodynamic properties like $\gamma$ and $R$.

Several types of LPRE cycles have been conceived regarding the manner in which propellants are fed to the main thrust chamber (compound of combustion chamber and convergent-divergent nozzle), but the main elements in a LPRE cycle remain the same:

- Propellant tanks: cryogenic or not (low temperatures preferred for low-density propellants such as hydrogen).

- Pipe lines: ducts joining the different elements.

- Valves: control components guiding and/or regulating propellants flow through the system. They can for example feed combustion chambers, serve as by-pass elements, as safety relief devices, etc.

- Combustion chamber (CC): cavity where combustion occurs. Combustion can be either spontaneous (hypergolic propellants) or not (external ignition required). Even monopropellant mixtures can be burned.

- Nozzle: component whose convergent-divergent geometry provokes the expansion of a highenthalpy flow and the consequent thrust generation due to the elevated mass flows and speeds attained.

The main factor influencing the cycle selection is propellants injection pressure, which determines the maximum pressure achievable in combustion chambers. Pressure-fed cycles can provide at most the same pressure at which propellants are stored. If pressure regulators are joined to tanks, a constant injection pressure can be furnished. Otherwise, a so-called blow-down operation with a decaying pressure is given.

If a turbopump subsystem is added to the engine, greater pressures than in tanks can be provided to chambers. Pump-fed cycles are therefore more powerful, since greater chamber pressures and hence thrust can be generated. However, they entail a higher complexity. A further classification can be made depending on the way of driving turbines, necessary to turn pumps and increase input flow pressure. The most used pump-fed cycles are expander, gas-generator and staged-combustion cycles. The former directly uses propellant flow to drive 


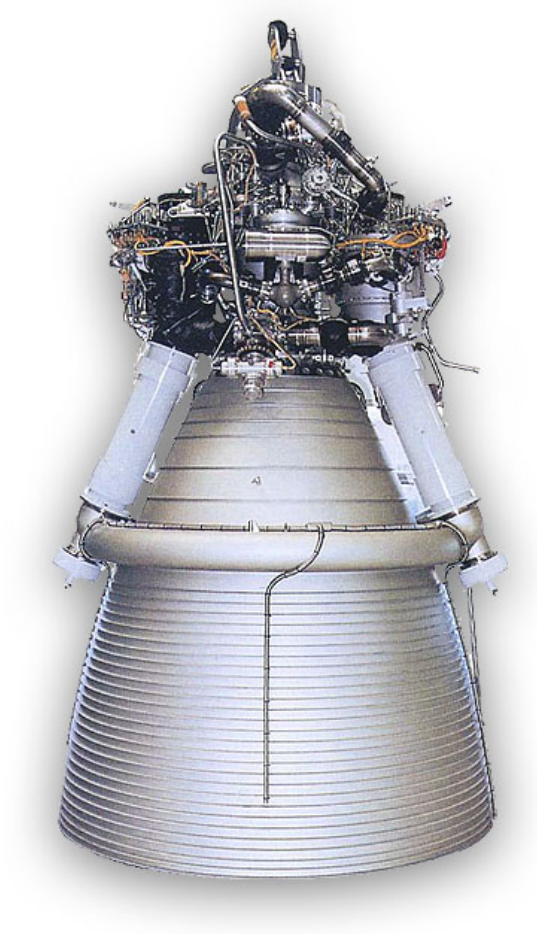

(a) Vulcain 2

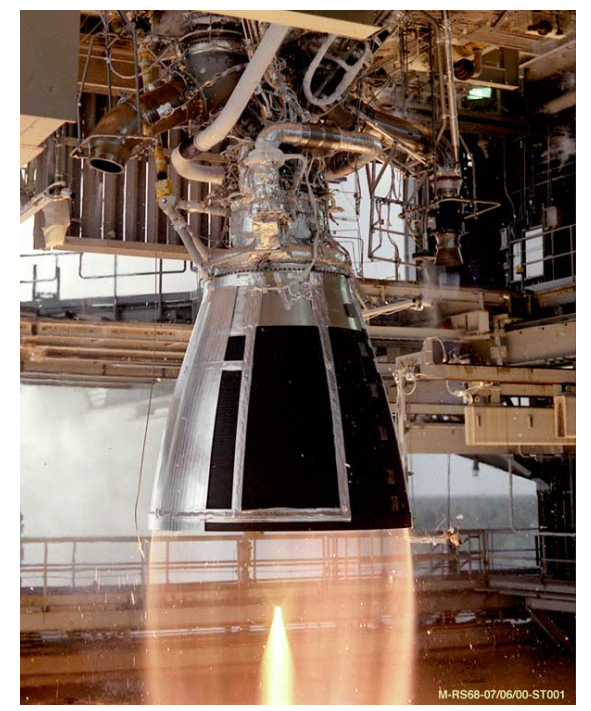

(b) RS-68 at test

Figure 1: LPRE examples

turbines, but it must first flow through a regenerative cooling circuit around the combustion chamber. Gasgenerator (GG) ones make use of the equally-named additional component to burn a low portion of propellants and feed its output to the turbine. That output flow is then exhausted or redirected to a downstream part of the thrust chamber. Fig. 2 depicts that generic cycle. The staged-combustion is similar, but pre-burners output is directly fed to the main chamber to be burned together with more pumped propellant. Depending on the family of engine cycles, different start-up times are given. Pressure-fed ones are faster (3 to $15 \mathrm{~ms}$ ) since they only include the operations of purge, valve opening, combustion initiation and pressure buildup, as explained in the book by SutTon AND Biblarz [2]. In contrast, turbopump-fed cycles obviously require more time ( 1 to $5 s)$ for starting a gas generator or preburner and accelerating shafts. These cycles generally require more complex control systems, owing to the greater number of operations and components, and especially to the higher amount of flow-control valves. Therefore, the vast majority of control studies reviewed in this article are devoted to pump-fed LPRE.
Transient phases, like start-up, are very accurately planned, fitting engine's characteristics and ignition type. Depending on the LPRE cycle, different sequences are planned. A typical start-up sequence for GG engines, such as the European Vulcain 2, begins by activating the starter related to GG and turbines, which increases pressure in GG so as to start driving the turbines. Next, with turbines turning faster, mass flows start to increase, allowing the opening of main chamber valves first and GG valves subsequently. The first chamber valve to be opened is normally the fuel one, due to two reasons: fuel must first flow through the regenerative circuit and a fuel-rich environment in the chamber is normally desired. During this low-regime phase, a pyrotechnic igniter is employed to trigger combustion in the main chamber. The opening of GG valves provokes the most intense pressure-increase phase in the start-up. Several characteristics have to be taken into account when dealing with start transients [3]. Energy and timing characteristics are vital and have to be evaluated and optimised. The influence of external initial conditions or perturbations, such as a start-up in vacuum, must also be assessed, with the aim of avoiding complex 


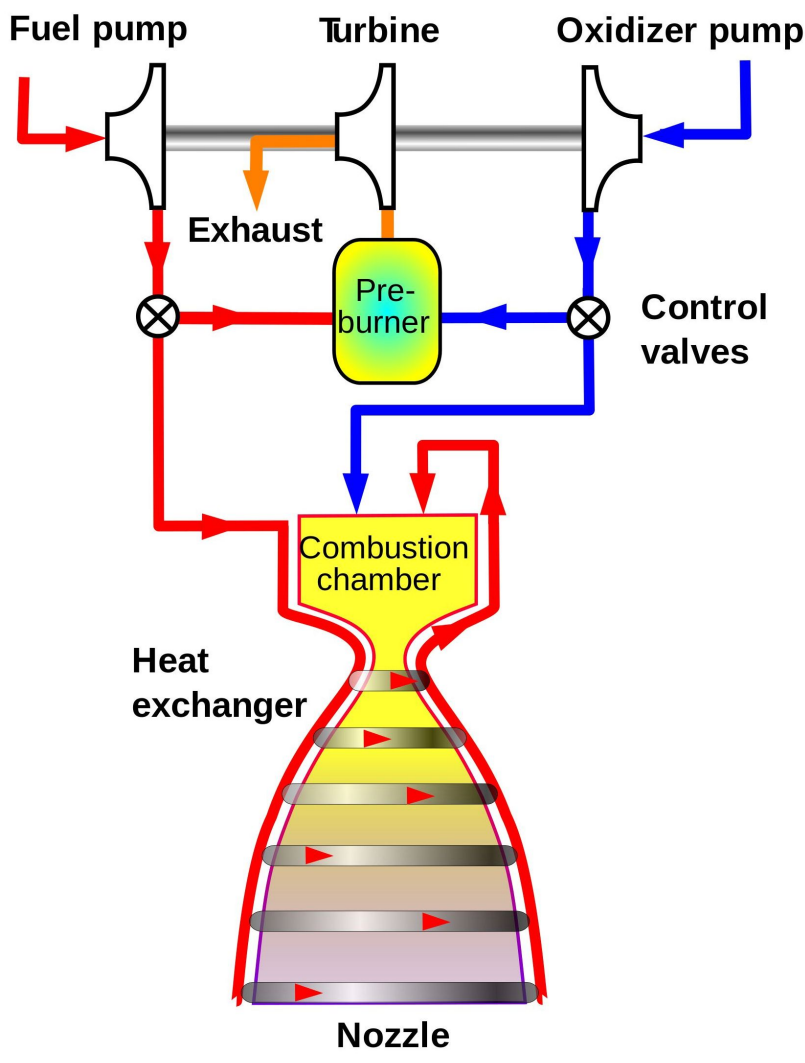

Figure 2: Schematic of a LPRE GG cycle by $D u k$, under CC BY-SA 3.0

and problematic phenomena such as unwanted pressure drop, stall, surge, cavitation, changes in fluid density, etc. The type and quantity of control components and some operating constraints are determined by all these features.

However, the goal of attaining a smooth and reliable ignition, lacking of pressure and temperature peaks, is the main driver in the off-line and generally constant planning of the start-up sequence, adapted to each engine. For instance, ignition overpressure is due to excessive ignition delay times [4]. If ignition is delayed, too much unburned propellant cumulates in the chamber leading to deflagration combustion once ignition finally starts. These pressure peaks may cause back-flows into the feed lines, probably becoming catastrophic. Temperature peaks are not that critical at this phase since the engine normally comes from a chill-down phase.

The shutdown process also presents some constraints, primarily related to some mixture-ratio limits, but is generally more simple to conceive. Other transient phases consist in throttling from one operating point to another. Traditional LPRE have been designed for a constant thrust level, but current reusable designs tend to allow a set-point variation, generally forced by new launcher requirements. All these transient phases might not be conceived as completely fixed sequences in the new engine designs.

\subsection{Context of current launcher programmes}

The context of LPRE cannot be addressed without making reference to the vehicles they mainly propel. Current design trends of space launch vehicles are leaning towards reusable conceptions. Indeed, affordable access to space requires reliable and safe reusable transportation systems presenting maximum thrust-toweight ratio and specific impulse. The economical and logistic advantages of reusable launchers have already been detected by several public and private agents around the globe. For instance, Soltani et al [5] point to cost reductions, return capability enhancement and less environmental impact.

Many conceptions have been formulated, such as launchers based on combined propulsion systems joining air-breathing and rocket engines (turbo-rockets, scramjet-rockets, etc.). However, the current developments and tests of reusable launchers still rely on rocket engines, as shown in fig. 3. Namely, two USAmerican companies are currently taking the lead in launcher reusability: SpaceX [6] and Blue Origin [7]. The former is developing heavy launch vehicles: Fal$\operatorname{con} 9$, with proven reusability of its first stage, and the already tested Falcon Heavy. Indeed, that company has identified the reuse of booster stages as a recurring cost reduction possibility [8]. BLUE ORIGIN, more focused on space tourism, has also recently demonstrated this functionality, but in this case their full small New Shepard launcher is reusable.

Japanese programmes are starting to deal with reusability by conceiving in-flight technology experiments and by mastering orbiter technology, as explained by Baiocco AND Bonnal [8]. Indeed, JAXA (Japanese Aerospace Exploration Agency) and Mitsubishi Heavy Industries [9] are developing a small reusable sounding rocket $(100 \mathrm{~kg}$ to $100 \mathrm{~km})$ propelled by four $\mathrm{LOX} / \mathrm{LH}_{2}$ (liquid oxygen liquid hydrogen) engines aiming at reaching a reusability target of 100 flights, thanks to both thrust control and health monitoring techniques. A recent Russian project, also indicated in reference [8], is the Baikal one [10], envisaging a reusable booster based on $L O X /$ kerosene propelled by the $R D-180$ and $R D-191$ engines.

With regard to the European developments, there have been some ESA (European Space Agency) projects 

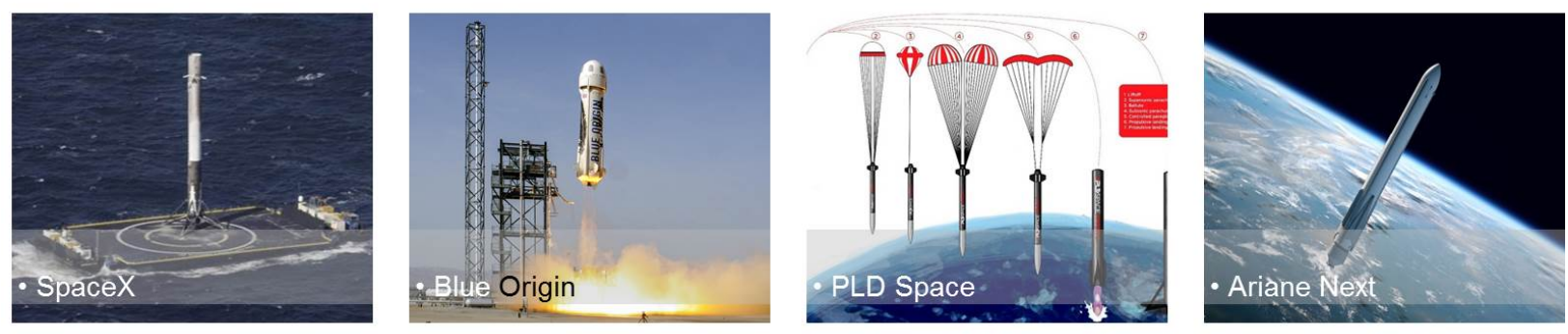

Figure 3: Main agents in the current context of reusable launchers

for reusable spacecraft, such as Hopper [11], a cancelled spacecraft with horizontal take-off and landing. It would have presented a non-disposable primary stage and an expendable upper stage. Recently, an ESA future launcher preparatory programme has been assigned to Spain's PLD SPACE [12], in the domain of small satellites launches. Furthermore, European projects for heavy launchers beyond Ariane 6 (collaboration between ESA, CNES (Centre National d'Études Spatiales) and ArianeGroup), for which reusability was not considered profitable [8], are now contemplating this feature as a way of adapting to the evolving market. Some ideas for the design of the future Ariane NEXT might come from the research studies performed on the Callisto reusable launcher demonstrator [13], a collaboration between European industries and institutions and JAXA.

All the mentioned companies and institutions are tending to see launcher stages reusability as a way of reducing launch recurring costs. However, there are some limiting factors to consider too. First of all, if the booster is to fly back to Earth, additional propellant mass has to be loaded. Then, scheduled maintenance is a necessity in these vehicles, contributing to raise the costs. Critical components are inspected and replaced if deviations reach intolerable values. That was the case for the most famous semi-reusable launcher, the Space Shuttle, which required comprehensive maintenance and replacements after each mission. And its engine was not an exception.

\subsubsection{Reusable rocket engines problematic: motivation of control enhancement}

The first example of reusable rocket engine which usually comes to mind is the Space Shuttle Main Engine (SSME), consisting in a satisfactory design being able to propel the US-American shuttle. However, this staged-combustion $\mathrm{LOX} / \mathrm{LH}_{2}$ engine presented several endurance issues which led to a non-optimised and expensive maintenance [14]. These issues, most of them being of thermal nature, were partly related to the type of propellant chosen, being cryogenic and of low density. These are some of the reasons why the future European reusable engine Prometheus is expected to run on methane $\left(\mathrm{CH}_{4}\right)$ [8]. This engine, currently under development, consists in a GG cycle with a single turbopump shaft. It is expected to attain $950-1000 \mathrm{kN}$ of thrust, and $I_{s p}$ (specific impulse) between $326 s$ and $366 s$ [8], depending on the stage where it will be placed. A 5-time reuse and two to four ignitions per flight are envisaged. In addition, these new engines also require throttling capabilities so as to meet reusable launcher's mission objectives. As explained by CASIANo et al [15], LPRE designs generally consider constant-thrust operation, with small variations around the equilibrium point. But many scenarios exist where throttling would be necessary: planetary entry and descent, space rendezvous, orbital manoeuvring, hovering or hazard avoidance. The fact that throtteable LPRE are able to continuously adapt to the optimal (most fuel-economical) thrust curve ensures best vehicle performance, in comparison to discrete variations. In that reference [15], different throttling methods on US engines are presented such as special injectors (high-pressure drop, dual-manifold, variable area, etc.), and complex techniques (pulse modulation, multiple chambers, throat throttling). They enumerate several quantities and parameters which can be used to vary thrust: propellant flow rates, propellant types and composition, and nozzle exit and throat area. However, they also state that the most common way of tuning thrust is regulating the propellant flow through control valves. This review confirms that this is the main strategy found in the literature, as it will be discussed throughout the article. The main issues concerning down-throttling that reference [15] points out are: combustion and system instabilities (mainly caused 
by suboptimal injection), performance deterioration, excessive heat transfer and pump dynamics, which are typical problems in reusable engines.

This propulsive feature can be illustrated with examples. For instance, the low throttling capability of BLUE ORIGIN's BE-3 (18\%) [7] simplifies their vertical landing process. SpaceX latest engine, the Merlin $1 D$ Vacuum, is said to throttle down to 39\% [6]. Each engine of JAXA's reusable sounding rocket alone is said to be throtteable per se from $40 \%$ to $100 \%$ of thrust, enabling a vertical landing of the launch vehicle [9]. Their expander-bleed cycle is indeed required to be restartable, avoiding ignition problems related to moisture freezing. SSME presented a [50\%, 109\%] interval for thrust and [5.5, 6.5] for mixture ratio [16].

All the aforementioned new capabilities of newgeneration LPRE (reusability, throttling, multi-restart) render their operation more complex, and this might not be accomplished with simple control systems. Indeed, facing the reusability requirement implies stronger robustness requirements on the control system, the system in charge of ensuring a correct behaviour of the engine. Let us bear in mind that the better the control system maintains the desired engine behaviour, the better its end-of-mission state will be, which is decisive for reusability. Those demanding requirements mainly arise from the greater perturbations that can take place: increased endogenous perturbations due to possible components faults or evolving parameters and exogenous perturbations related to the mission profile, also more complex in reusable launchers. The multirestart capability during flight also toughens robustness specifications in the same sense. Regarding throttling, the classical linear multivariable control attains a reduced envelope around the steady-state nominal point, between $70 \%$ and $120 \%$ according to [17]. Thus, an enlarged controller-validity domain should be attained for safely reaching low thrust levels, considering the different regimes of operation of the engine. All in all, it can be said that the potential need for reusable launchers and their associated engines represents a real challenge for control-system designers, which motivates this survey paper. To the authors, it seems necessary to recapitulate and analyse the state of the art of LPRE control in order to face this challenge.

\subsection{Outline}

The structure of this survey is the following. Section 2 serves as an introduction to the generalities of LPRE control systems: their purpose, their main parts and which variables are generally controlled through which inputs. Besides, the primary and secondary control loops are described, and also a series of advanced control-system conceptions applicable to reusable engines are introduced. The core sections, containing a detailed review of all articles, including academic and industrial contributions, are Review of modelling for control and Review of control methods. Approaches are structured according to the different fields in automatic control: Identification and modelling, Sensors and actuators considerations, Analysis (contained in Section 3), and control techniques (in Section 4). The subsequent Summary and discussion section relates all approaches and observations to one another. Section 6 contains the concluding remarks and the discussion of future control design trends.

\section{LPRE control systems background}

After having described the generalities and context of rocket engines, the main scientific topic of this paper can be introduced.

Chamber-pressure and mixture-ratio control was achieved in test-benches as early as in 1959 by Отто AND FLAGE [18], by means of an analogue model-based PID (Proportional-Integrator-Derivative Controller) approach on a regeneratively-cooled hydrogen-fluorine rocket engine. Results during the start-up transient of this pressure-fed engine were successful with a maximum of $\pm 2 \%$ deviation. Stoichiometric mixture ratios, which are generally related to maximum combustion temperatures, were well avoided.

Before the spread of electronic controls for controlling engines, these used to be pneumatic and powered with helium gas. This gas is still employed for secondary tasks within the engine, although not for control. Simple timers were employed in the early engines to send actuation commands and later they developed into pressure ladder sequences.

In the last decades, automation in propulsion systems has evolved and comprises system engineering, control and health monitoring. Firstly, a multi-physic modelling approach is customarily carried out, joining chemical, hydraulic, electrical, mechanical, thermal and structural aspects. Each new engine design presents a different behaviour. Hence, each type of rocket engine cycle requires a specific control approach. A minority is naturally unstable, others are stable but with non-minimum-phase properties or present varying parameters. In other words, the selection of the most adequate control system depends on system's requirements, accuracy, dynamic characteristics and reaction-time constraints, which are normally defined 
by mission's profile and by the whole architecture of the propulsion system. For instance, the environment has to be carefully analysed, taking into account all sources of perturbation (accelerations, propellant temperature variations, etc.).

As pointed out by Le GoNIDEC 2017 [17], engine control systems rely on components such as hydro-mechanic devices or flow rate controllers in order to improve performance in terms of accuracy, response time, perturbation rejection and reliability. The in-flight control should ensure a simplification of testing and flight preparation, allowing thrust modulation and versatility.

In a paper by Bellows et al from the RocKETDYNE company [19], the need for a more reliable and coordinated control and health monitoring system for rocket engines is highlighted, already in 1984. A reference is made to SSME engine-mounted programmable control system, which managed redundancy, a severe environment and real-time constraints and offered flexibility. The actuators of this staged-combustion-cycle consist in a set of valves, and sensors are flowmeters and pressure transducers. The complexity of the LPRE control problem can already be inferred from the fact that only two actuators (control valves upstream from pre-burners) are used to control the system in a continuous way, while the rest of valves are open or closed according to high-level configuration orders. These signals are usually a part of sequential processes, often modelled as automata [20].

The paper by Seitz and Searle [16] explained how the first SSME control system was designed during the seventies. Apart from ensuring monitoring and fail-safe operation, the system could perform repeatable start, steady and shutdown operations during 100 runs. At this staged-combustion engine, thrust and mixture ratio are controlled by correcting the power repartition between turbopumps, regulated by the preburner oxidiser valves (characteristic of staged-combustion cycles). During the start-up transient, closed-loop (CL) control of thrust starts pretty early while mixture-ratio CL control starts later, as explained later in Section 3.3. Another loop monitors that certain temperature limits at turbine inlets are not reached by reducing the thrust command when necessary. At shutdown, CL is maintained until the minimum thrust level $(50 \%)$ is attained.

The European company ArianeGroup have put a lot of effort since the late 80's on the control of rocket engines, as explained in [17]. In 1988, control was only applied to test benches, such as the PF52, PF50 (France) or P5 (Germany), in order to regulate tanks

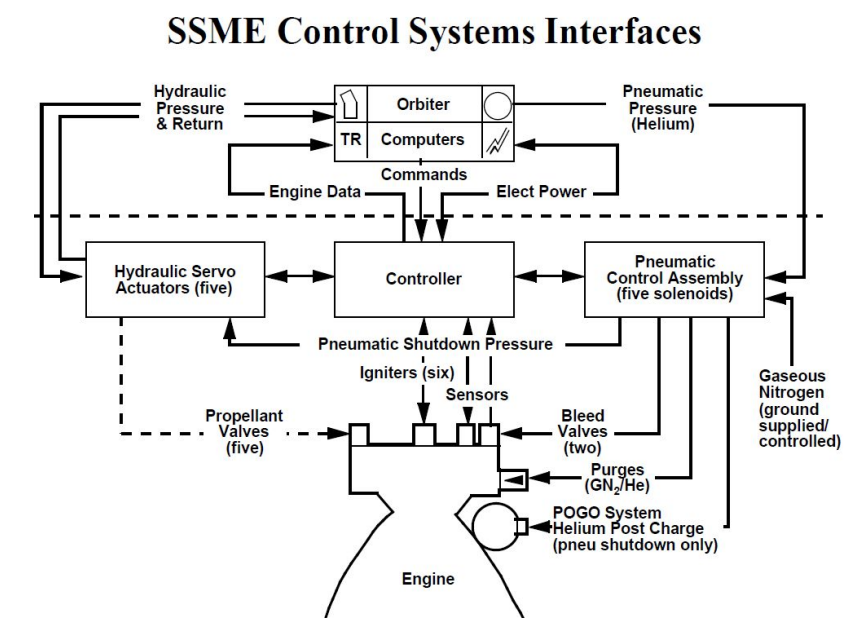

Figure 4: SSME control chart [21]

pressures and turbine speeds among others. The main purpose of this automation was to test Vulcain subsystems such as gas generators and turbopumps. Since 1994, control started to be applied to actual rocket engines, so as to maintain their stability (some of them are non-minimum-phase systems) and performance. It was mainly devoted to control Vulcain engines in a monovariable way. For the older generation of engines, HM7 and Viking, control systems simply consisted in hydro-mechanical loops. Due to the wish to improve the engine test performances (i.e. response time, reliability, accuracy, etc.), multivariable control was integrated in $2000(3 \times 3$ for Vulcain and $2 \times 2$ for Vinci). New-generation engines will make use of more electric systems, as initiated by Vinci (partially electric).

\subsection{Main control loops}

As hinted in the previous paragraphs, LPRE control entails a long list of control subsystems or loops, in charge of dealing with certain variables or flight phases by acting on the controllable inputs (valves, starters or igniters) and by measuring engine's state. But all of them are related by a common management entity such a computer or an orbiter, as depicted for SSME in fig. 4 from [21].

In order to generate a controlled thrust $F$ at a desired specific impulse $I_{s p}$, two level distinctions must be made according to [17]. At tank level, tank pressure must be controlled, and at engine level, chamber pressure and mixture ratio are the key variables. If the cycle contains a GG, more variables come into play. Indeed, the three main control loops in LPRE described in the book 
by Huzel AND HuANG [3] are: thrust-level, propellantutilisation and thrust-vector controls.

Thrust-level control: mainly governed by combustion pressure and hence by the total injected mass flow (as defined in (3)). This is the slowest loop, whose bandwidth is determined by thrust requirements. For constant-thrust engines, a tolerance of $\pm 3 \%$ is typically achieved by adjusting orifice sizes and by opening and closing propellant valves without the need for CL. Should a greater precision be desired, regulators or controllers have to be used in order to compensate variable conditions. And if throttling is needed, especially during the last propelled phases, chamber pressure reduction has to be implemented either stepwise or continuously. As commented earlier, varying the mass flow is not the only way to modify pressure and its related thrust. When looking at (1) to (3), one can see that throat area and $I_{s p}$ can also be varied, whereas $C^{*}$ remains nearly constant for a given propellant combination. $I_{s p}$ can be modified by changing the mixture ratio (coupling with $M R$ loop, explained in the next paragraph). Nevertheless, as stated by Timnat [22], this variation generally leads to performance deterioration. Throat-area tuning is also problematic since complex mechanical or aerodynamic techniques would have to be implemented, such as pintles or secondary injections, which would alter the cycle design and behaviour and hence performance [22]. The schematic by [23], shown in fig. 5 is a good example of a closed thrust-level control loop using valves, again applied to the SSME. Feedback of pressures, temperatures and volumetric flows is used to compute valve control orders.

Propellant mixture ratio and propellant-utilisation control: this regulation is needed to attain optimum engine performance (maximum specific impulse) and to save propellant resources. As stated in [3], it can be performed either in closed or in open loop. Open-loop control, apart from requiring orifices calibration, can be further refined by weighing the loaded propellants and by installing adjustable orifices. This is acceptable in engines naturally presenting good $M R$ (mixture ratio) tracking, such as single and first stages. In contrast, $\mathrm{CL}$ is needed at high-velocity-increment upper stages or restartable engines. In basic cases, $M R$ can be controlled by adjusting the main oxidiser flow valve alone, typically a servo-controlled one.

Reference [24] highlights that this loop should be faster than the thrust-level one so as to minimise high deviations, but attention to their strong coupling must be paid. As indicated by [2], it is common that LPRE are controlled to a constant $M R$, selected according to performance. However, in some cases this command could vary in order to improve propellant management, especially during the end of engine's mission. This is intended to empty tanks completely and hence reduce the mass of the spacecraft. But it is also normal that mixture ratio undergoes great variations during start-up and shutdown phases, where one of the propellants may lead and hence the ratio is not meaningful. Besides, propellant lines' hydraulic resistances are usually different, resulting in different filling times in the start-up transient. Thrust-vector control (TVC): an effective way of guiding a launcher is varying the direction of the generated thrust. Therefore, TVC is widely employed. Typical methods pointed out in [3] are gimballed thrust chamber, gimballed nozzle, jet vanes in the nozzle section, secondary injection into the thrust chamber and auxiliary jets.

Nevertheless, this subsystem, serving as an interface with the vehicle, lies beyond the scope of this paper. Other secondary but relevant loops explained in [3] and [2] are the following:

Duration control of main stage: includes tank low-level sensor and an accelerometer or similar device to send the cut-off signal.

Safety control: monitoring devices for combustion instabilities or over-temperature. An interruption of electrical power supply always triggers shutdown.

Tank pressurisation control: CL compatible with propellant-utilisation control and thrust control subsystems. Necessary for keeping the required pressure for a nominal operation of the engine.

Control calibration: proper settings of computer, devices, switches, etc.

Checkout and tests control: post-assembly and prefiring checkouts, allowing operation simulation.

System start control: a sequential start control includes systems preconditioning (purging, chill-down), valves opening, start energy activation and introduction and ignition of propellants in the chamber. Other secondary events may appear such as some related to gas generators or pre-burners. The start is either oxidiser-lead or fuel-lead in order to mitigate high-temperature peaks, depending on propellant combination and engine cycle. Between three to five seconds are normal durations of this phase. SSME start-up control strategy was in open loop (OL) during the first $2.4 \mathrm{~s}$ in thrust and $3.6 \mathrm{~s}$ in mixture ratio, when the respective PI (ProportionalIntegrator Controller) closed loops started [23]. Thanks to tests and simulations, nominal sequences are usually an off-line optimised trade-off between achieving the start of the motor and minimising damaging transients. But in reality the sequence of phenomena is very sensitive to external and internal conditions and character- 


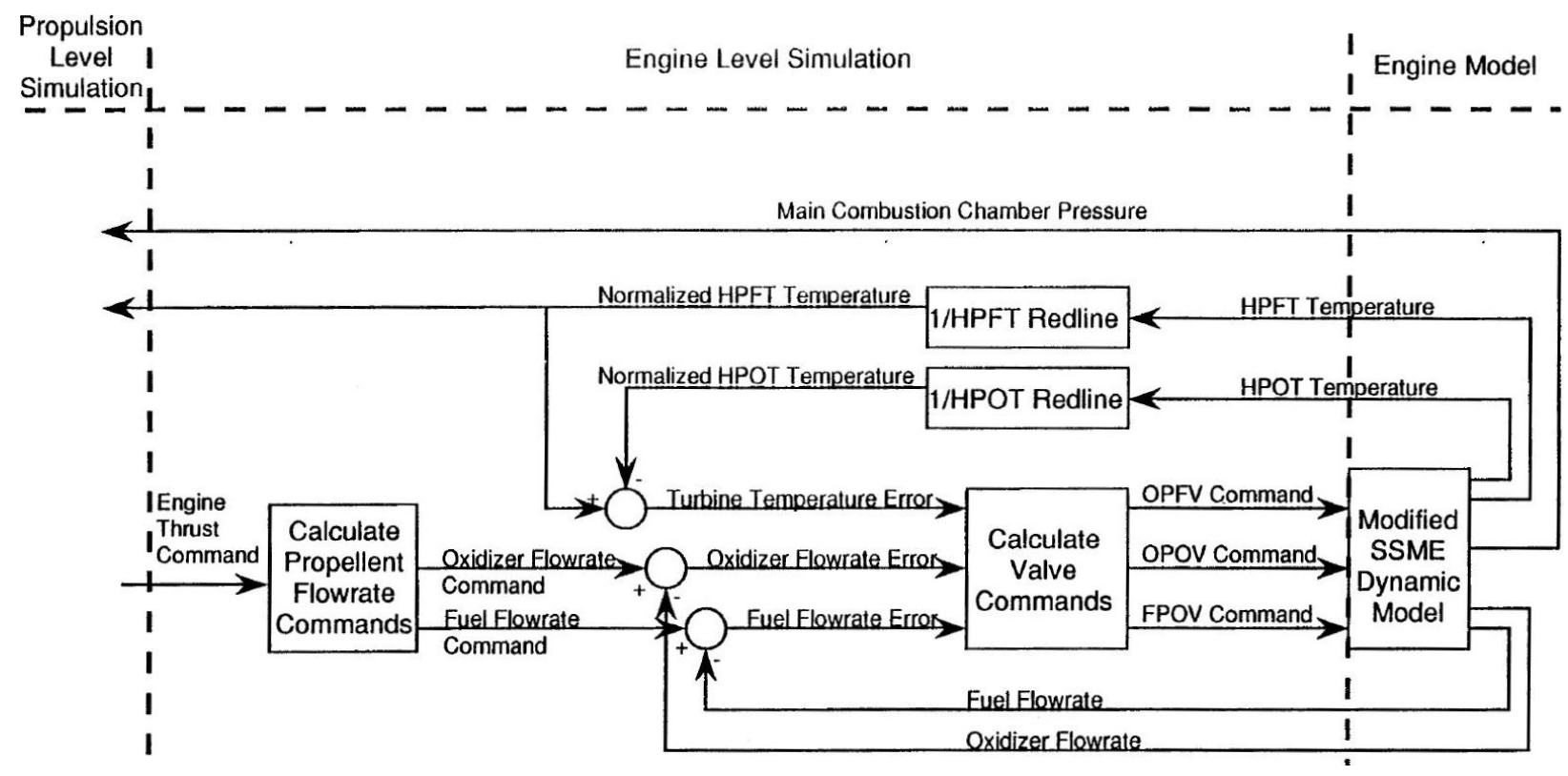

Figure 5: CL thrust-level control diagram, performed via valves (defined in Section 3.1) with turbopump-redlines verification by NeMETH et al 1991 [23]

istics. In OL, small changes might trigger longer transients or even an unsuccessful start, due to the highly nonlinear and coupled effects that take place.

System cut-off control: a quick and secure engine shutdown must be ensured. This shutdown concerns subsystems power, chamber flow rate and purges or flushes in the case of a test. A fuel-rich finalisation generally avoids high temperatures. Moreover, as indicated in [2], the amount of impulse provided by this last phase may have to be reproducible if the application requires an accurate final vehicle speed.

A current research topic, which would consist in another loop, is the precise control of the combustion phenomenon in order to avoid instabilities and enhance performance. Combustion instabilities of low and high frequencies arise when perturbations in velocity or pressure are enlarged by combustion heat transfer and produce acoustic energy periodically. That energy serves to amplify the perturbations, creating a self-sustained cycle. This poses important problems to the structure and performance of the propulsion system. The effects of low-frequency instabilities are mainly counteracted via passive methods implemented in LPRE combustionchamber designs, such as baffles, resonators or acoustic liners. In contrast, Active Combustion Control (ACC) is a recent methodology described by RTO/NATO [25] used in gas turbines for controlling combustion perfor- mance by means of dynamic hardware. This actuation hardware, which is generally pretty different to typical valves, is able to quickly adjust the combustion input in terms of injection timing instead of the traditional spatial distribution modification. Some research works concerning monopropellant rocket-engine combustion control via pintle devices or pressure regulators are $[26,27,28]$. However, that loop lies beyond the scope of this review, devoted to the control of the engine system as a whole.

\subsection{Reusable LPRE control trends}

It seems relevant to summarise some insights on advanced control-system conceptions applicable to reusable engines. As commented earlier, reusable engines would require these advanced concepts to a greater extent. The review by LoRENzo et al 1995 from NASA [14] provided insight into the control technology research trends potentially applicable to reusable rocket engines in the context of NASA's SSME: intelligent control, multivariable control, life-extending control and the Robust Rocket Engine Concept. These concepts were aimed at mitigating durability issues in future reusable engines, and would still be applicable nowadays. The SSME presented indeed issues with turbine blades, bearings, thrust chamber liners and propellant ducts. 
Intelligent Control System (ICS). This concept consists in a hierarchy of several control and diagnostic methods: life-extending control, reconfigurable control, realtime diagnostics, component-condition monitoring and engine prognostics among others. The mission-level control is the main director of the system, establishing thrust and mixture-ratio requirements. Then, the propulsion-level control must comply with propellantutilisation requirements, regulate tank pressures and provide thrust and mixture-ratio commands to the engine level control.

In the ICS design by Musgrave et al [29], model-based fault detection based on a modified model of SSME is successfully integrated and demonstrated in real-time. Different failure types are considered: freezing, limiting and leakage, but the focus is made on accommodating a frozen oxidiser valve at down-thrust and upthrust manoeuvres. The selected valve is in fact the critical element determining the main combustion chamber mixture ratio. In the event of a fault, the new maximum thrust is calculated depending on the valve position and this is transmitted to the propulsion management system. The global damage rate can be estimated by monitoring the turbine discharge temperatures, relevantly representing engine health. If they exceed certain values, the engine is considered to be degraded. Hence, ICS would lengthen engine life and permit degraded performance even on a multi-engine system.

The NASA-Rocketdyne report on the Reusable Rocket Engine ICS (RREICS) functional framework by NeMETH et al [23, 30] deals with a rocket engine cluster of three devices as a whole, distributing thrust and mixture ratio among each engine, depending on health, efficiency and on the ageing state of each motor (estimated from measurements via damage models). Diagnostic logics are implemented to define the allowable reference point for each engine according to those criteria. Seven valves can be open or closed but only two are fully controllable. Hence, different sets of valve commands can fulfil the control goal. At the same time, parameter ranges are respected via three secondary valves. The best combination is selected by the engine-level controller according to a cost function which depends on wear, risk of failure and performance losses. If redlines are reached, cut-off commands are sent to the valve sequence coordinator. The latter redefines the start sequence whenever there are failures so as to minimise the catastrophic risk.

Multivariable control. Single-loop control designs are simple and do not present demanding requirements. However, multivariable control can provide a more ac- curate regulation. In fact, rocket engine control is intrinsically a multivariable problem, generally stable in open loop and requiring mixture-ratio and combustionpressure control by means of several valves, typically achieved in a linear way. For instance, the design by [29], making use of the Linear Quadratic Gaussian loop transfer-function recovery (LQG/LTR) and $H_{\infty}$, has succeeded in stabilising the closed loops. The multivariable ICS by [23] studied the feasibility of CL control during the SSME start-up without success. The multivariable controller was aimed at rendering the system insensitive to parameter variations, perturbations or noise. But it was only effective after the transient, where it zeroes the error on turbopump discharge-pressures deviations, which is not a common strategy. These quantities influence the input flow to the main chamber and in the end determine thrust and mixture ratio. In fact, their commands are translated from thrust and mixture ratio errors.

Life-extending control (LEC). The amount of cumulated damage at critical points can be significantly reduced by an appropriate control during these periods. A life-extending control system is presented in the 2001 paper by LoRENzo et al [31], aiming at accomplishing high performance and structural stability. The key approach is damage mitigation, performed in both turbines of SSME $\left(\mathrm{O}_{2}\right.$ and $\left.\mathrm{H}_{2}\right)$ achieving positive transient results in the two outputs: chamber pressure and mixture ratio. Both linear and nonlinear control techniques are employed. In conclusion, after a small loss in performance, the engine life can be relevantly extended, reducing damages. However, their damage modelling does not take into account high-temperature effects.

Indeed, feeding damage rates back and using nonlinear optimisation is the key to minimising damage (fatigue/fracture and creep) at critical phases, according to [14]. There is the need for nonlinear filters since the relation between local stress and damage rate is so. This way, the damage produced during transients is said to be divided by three at least. The drawbacks are increased computation and sensing.

Robust Rocket Engine Concept RREC. Extending LEC, a multidisciplinary optimisation can be carried out to reduce even more damages during the critical transient phases (start-up and shut-down). This optimisation would concern the operating cycle, critical components like turbine blades, transient control parameters and endurance issues. This conception has only been suggested by LoRENzo 1995 [32]. However, it would imply greater computation times and maybe dynamic response 
and propellant usage would be penalised.

No NASA follow-up studies putting in practice the aforementioned concepts on reusable engines have been traced in the literature. Nevertheless, outside NASA some multivariable approaches on nonparticularly reusable engines have been published; and the next sections present them, as well as previous works.

\section{Review of modelling for control}

This section together with the following one, Review of control methods, consist in the core sections in this article, since they contain the detailed review of articles, including academic and industrial contributions. Approaches are structured according to the different fields in automatic control. This section covers identification \& modelling, sensors and actuators considerations and system analysis. The greater abundance of research publications during the nineties and the early 2000's coincides with the operation of the SSME and the observation of its reusability problematic. Afterwards, not many recent papers have been published.

\subsection{Identification and modelling}

This subsection outlines model design and identification methods. Derivation of control laws for this type of systems is most often accomplished via modelbased approaches. The main thermodynamic assumptions made are mentioned, but comprehensive explanations on thermo-fluid-dynamic modelling are not the main focus here.

The physics of rocket-engine components are generally described by means of thermo-fluid-dynamic and mechanical conservation equations. Terms are generally not developed in their full complexity since the most precise model is not the target. It is preferable to manipulate a tractable model for deriving control laws. The three flow equations are the typical mass (or continuity), momentum and energy conservation equations. The mass-conservation equation, applicable to capacitive elements like cavities, can be written as:

$$
\frac{d}{d t}(\rho V)=\dot{m}_{\text {in }}-\dot{m}_{\text {out }},
$$

where $\rho$ is density and $V$ is volume. The momentum conservation equation comes from the equilibrium of forces in a fluid line inside resistive elements like valves or pipes $[33,4]$ :

$$
\left(\frac{L}{A}\right) \frac{d \dot{m}}{d t}=p_{\text {in }}-p_{\text {out }}-k_{\text {res }} \dot{m}|\dot{m}|,
$$

where $L$ is length, $A$ is area and $k_{\text {res }}$ is the corresponding resistance coefficient. The quotient $L / A$ is the inertia of the element. Finally, the energy-conservation equation is again applicable to capacitive elements [34]:

$$
\frac{d}{d t}\left(\frac{p V}{\gamma-1}\right)=\left(H_{\text {in }} \dot{m}_{\text {in }}-H_{\text {out }} \dot{m}_{\text {out }}\right)+\Phi,
$$

$H$ being enthalpy and $\Phi$ being the heat transferred through the walls (received or sent). Regarding turbopump mechanics, the shaft usually presents a mechanical differential equation on its rotational speed $\omega$ :

$$
\frac{d \omega}{d t}=\frac{T q_{T}-T q_{P}}{I_{T P}}
$$

where $T q_{T}$ is turbine's generated torque, $T q_{P}$ is pump's consumed torque and $I_{T P}$ is shaft's angular inertia. However, in the industry, models can also be built thanks to multi-physical simulation platforms, such as CARINS by CNES/ONERA [34]. Due to the progress in terms of modelling tools, linear state-space models can sometimes be automatically derived from multiphysical nonlinear models [17], which avoids in some cases the manual derivation of engine's equations.

\subsubsection{Linear identification}

Instead of developing a model for control from thermodynamic equations, some authors have opted for identifying it from simulations or tests. The dynamic behaviour of the SSME was identified by DUYAR et al [35]. The open loop considers the opening angles of its main five valves as inputs, and six outputs apart from the typical two: pressure, temperature and speed of both HPT (high-pressure turbines). Preliminary information on the system's nonlinearities and bandwidths is obtained by exciting the open and closed loops. The fuel preburner oxidiser valve (FPOV) and the oxidiser preburner oxidiser valve (OPOV) are identified as the dominant ones, which allows the removal of the other valves from the open loop. Indeed, these dominant valves are regulated in all main SSME control publications $[23,16,29,36]$. A pseudorandom binary sequence (PRBS) is used as perturbation signal for identification. It consists in a wideband long-duration signal switching from one to another value. A step signal with a $2 \%$ amplitude PRBS is employed as the driving signal for the CL. Responses point to the presence of valves nonlinearities, but these can be isolated and even removed for identifying the main system.

By linearising the equations, the following transferfunction structure is taken as the base for parameter estimation between the $j^{\text {th }}$ actuator and the $i^{\text {th }}$ sensor:

$$
H_{i j}(s)=C_{i}(s I-A)^{-1} B_{j},
$$


where $A, B$ and $C$ are the standard state-space matrices and $s$ is the Laplace variable. The recursive maximum likelihood method (RML) is the selected approach, determining the transfer function $H(s)$ coefficients from input and output data by subtracting the nominal values from the perturbed ones. The order of the model must be predefined. Consequently, the authors follow the parsimony principle, selecting the highest order at which the further error decrease is negligible. Results after nonlinear simulations pointed to good representativeness around a limited-response region about the $100 \%$ thrust level, but the nonlinear effects of valve linkage backlash and valve stiction (static friction) were not considered, recommended to be included in future models.

Valves modelling in [18] was performed through identification after testing real devices. Dead times were considered between valves and sensors, capturing the time required for a pressure wave originated at the valve to arrive at the sensor. This causes a phase lag with no change in amplitude. Engine dynamic response is flat after $100 \mathrm{~Hz}$. The equation of pressure variation is obtained in a simple way by combining static equations. The least-squares (LS) method can also be used for model identification based on data coming from complex simulation platforms.

\subsubsection{Linear thermodynamic modelling}

Some approaches directly tackle linear models, usually already in the frequency domain. The linear model by [37] handles the flow through pipelines. Gases are considered ideal, expansion is isentropic and regulators are ideal mechanical systems. In the feed lines, liquid propellant is treated as compressible but not in injectors. The combustion chamber is considered as a vessel with time delays for injection, mixing and combustion. The last phenomenon is treated as ideal, with perfect burning.

That model comes from previous work by the same research group [38, 39], in which a model block diagram in the frequency domain is established. The components described in those papers are the combustion chamber, the injector head, cooling jacket and pipelines, which are modelled linearly at the nominal operating regime.

\subsubsection{Linearised models}

The most common modelling-for-control approach in LPRE is linearising a nonlinear thermodynamic model. The reusable-engine model used in [29], based on nonlinear mass, heat and power equations, comprises four turbopumps, three combustors, two multiphase heat exchangers, a nozzle and pipes, adding up to 40 states.
However, it is later linearised for deriving a control law, as detailed in Section 4.6.

Regarding the also reusable engine modelling by [31], similar to the SSME, standard lumped parameter schemes have been applied for approximating the partial differential equations related to mass, momentum and energy conservation as first-order ones. Causal interconnections are defined to join all the engine's subelements, which results in a plant model of eighteen states, two control inputs and two outputs. However, the model is linearised around $p_{c}=176 \mathrm{bar}$ and $M R=6.02$ and reduced to a 13-state model via the HANKEL order reduction. Physically speaking, both turbopumps speeds are controlled by the corresponding preburner pressure, and so propellant flow is determined. The oxygen mass flow into the pre-burners is individually handled by two flow control valves (FCV). In another paper by these authors [24], it is claimed that the linear models of that engine did not present relevant variations while throttling, suppressing the need for gain scheduling.

McDermott et al [40] obtained an analytical dynamic model of the small Surveyor engine, which is throtteable. This pressure-fed bipropellant engine covers a thrust range between 133 and 462N. They linearised the model, which rendered it only accurate for small amplitude variations about the operating point. However, real CL results pointed to adequacy for large thrust deviations. The transfer function obtained in the end expresses thrust variation as a function of variations in fuel and oxidiser flow rates.

Although the work of Bergmans And Myers [41] is devoted to a solid-propellant GG which runs an air turborocket engine, it is relevant to comment on their decoupled SISO (single-input single-output) modelling approach. They derived first a nonlinear model of the GG and its outlet nozzle by means of the standard conservation equations (applied to solid propellants) and of subscale test data. The transfer function between valve area and outlet pressure is obtained after linearising the nonlinear model about a pressure which is not the steadystate one but is not far from it. This linearisation proves to be valid within a pressure range of around 35bar.

The modelling approach by SolTANI et al [5], even if devoted to fault detection and isolation (FDI), shares the same philosophy as control-oriented models. Their overall nonlinear model includes valves, pumps, a generator and the combustion chamber. It contains fourteen inputs, eighteen outputs, fourteen non-measurable variables and six continuous states. Twelve failure cases are considered, but the complexity of the system is too high to perform a reasonable monitoring. Hence, the structural analysis method is employed to divide a launcher 
propulsion system into simpler sub-elements in order to perform an easier and more specific FDI design. Its qualitative nature, abstracting system's behaviour, provides sub-components identification, residual design capability and reconfiguration possibilities.

Simple linearised models for valves, injector (including mechanical elements like masses, springs and dampers) and the combustion chamber are employed by ZHоU [42], allowing the definition of a relatively compact transfer function of the whole engine system. A constant combustion delay, expressed in terms of injection and ignition delay (less than $5 \mathrm{~ms}$ ), and ideal gases are considered.

In the report by Le Fur et al [43], the modelling and control of an expander-cycle rocket engine is tackled. Since their objective is analysing low frequencies, capacitance, inductance and combustion dynamics are not considered. The computation of an equilibrium point at some given valve gains is performed via a model of 19 static equations and unknowns: two turbopump speeds, four mass flows, five temperatures, seven pressures (CC, cooling inlet and outlet, turbine inlet and outlet among others) and mixture ratio. That system of equations is nonlinear and some equations are implicit. It is solved by defining a mesh of chamber-pressure and mixtureratio values.

However, their simplified state-space representation only integrates seven states: rotation speeds, chamber pressure, the gains of the two control valves (turbine bypass) and their derivatives. Control inputs are the two corresponding opening positions. Some exogenous inputs are also considered: pump inlet pressures and pressure drop coefficients of chamber valves (not controlled). Besides, there is a set of algebraic equations (eleven) related to some intermediate variables, states and exogenous inputs. Measured outputs are considered to be only rotation speeds, since they are the variables which can be directly controlled by turbine bypass valves. All variables are normalised to their nominal values.

Linearisation around the previously computed equilibrium points is then performed on this model, since three of the equations are nonlinear. These equations are precisely the only ones not depending on control inputs. The presence of algebraic equations complicates the process, attaining a matrix of dimension 99.

Further examples of linearised models can be found in [44], [45], or in [26] and [27], where the Crocco monopropellant combustion model [46] is used.

\subsubsection{Describing functions}

Nassirharand AND Karimi [47] succeeded in controlling the mixture ratio of a LPRE making use of a systematic describing-function method together with factorisation theory. The controller is designed for a linear plant coming from the chosen methodology. These results may allow the substitution of complex hydromechanical control valves by simple ones driven by microprocessor-based servomechanisms. However, these techniques are only applicable to engines whose main control loops (chamber pressure and mixture ratio) are decoupled, which is not the usual case.

Indeed, the idea behind describing functions (DF) is to represent nonlinear systems as linear time-invariant transfer functions which depend on the amplitude of the input signal. This generally translates into considering a set of linear systems, simplifying the initial problem at a said satisfactory robustness level. Concretely, sinusoidal-input DF (SIDF) models are employed in [47] for several reasons. Firstly, standard linear models do not represent correctly the amplitude dependency of the full plant. Other models such as random-input DF neither capture the dependency of the nonlinear statespace plant at the desired frequencies. Thus, a set of SIDF is considered as a safe base for a robust control without renouncing to performance. Besides, these functions are defined by just one parameter, the amplitude of excitation, reducing the design complexity. Basically, these models are obtained by considering a sinusoidal excitation of the plant and by computing the FOURIER integrals of the nonlinear equations of motion.

\subsubsection{Nonlinear modelling}

In general, rocket-engine models in their nonlinear form without linearisation have only been used for simulation and/or analysis, not for deriving control policies. In this sense, a performance model simulating Vulcain's internal flow characteristics (pressure, temperature and flow rate) was developed by IfFLY AND BRIXHE within SNECMA Vernon (which became part of ArianeGroup) [48], with the collaboration of Techspace Aero. The main input data to the model are pump-inlet pressures and temperatures, geometric and thermal features and valve settings. Twelve unknowns are considered: thrust chamber and GG mass flows, dump-cooling mass flow, pumps rotational speed, turbine-outlet pressures and temperatures and $\mathrm{H}_{2}$-turbine mass flow. Solutions are attained iteratively.

Engine parameters in the previous model are obtained by data reconciliation with tests, that is to say, by estimation through generalised residual sum of squares (Gaussian assumption). Discrepancies of two origins 
are taken into account: test-measurement uncertainties and balance of physical equations. Operating ranges are also computed. These consist in the set of operating points reachable with a certain probability, considering elementary dispersions following gaussian laws on engine parameters. The method employed is a time-efficient Monte Carlo scheme, taking engine's behaviour as linear. With this linear model, a covariance matrix can easily be calculated, allowing to draw an isoprobability locus at each operating point. By joining all these ellipses, a full flight envelope can be drawn. Operating limitations can also be calculated by introducing a constraint and then determining the valve configuration respecting this constraint. An accuracy of around 1\% on the basic model parameters is attained.

SAINT-MARD et al [49] developed a nonlinear model of a turbopump-fed LPRE for simulation. On this model, also valid for transients, feasible working points are identified and requirements in terms of control-devices' OL accuracy are indicated. It presents some algebraic equations such as chemical reaction ones, including mass conservation, equilibrium equations and enthalpy conservation. In addition, it contains iterative loops for certain components like the nozzle. It is subject to operating constraints on mixture ratio and turbopumps's speeds. Concretely, mixture ratio must stay away from the stoichiometric value and critical shaft speeds must be crossed quickly so as to avoid eigenfrequencies and over-speed, which are common practices in LPRE.

ZhANG 1984 [50] applied the state-space framework to the analysis of the dynamic characteristics of a variablethrust LPRE, obtaining results agreeing with experimental data. The engine concerned presents a pressurefed cycle, whose injected flow in the chamber can be modified by varying the displacement of a springpintle compound. This is accomplished by means of a so-called variable-gain solenoid-valve hydraulic control system, used to adjust that pintle position with two valves. The considered delays in valves operation concern current-raising and piston-moving times. Seven states are selected for the nonlinear model: chamber pressure, gas mixture ratio, injected mass flows (two), and pintle's displacement and velocity. Combustion chamber follows a single-time-delay model, in which homogeneous mixing and ideal gases are assumed and droplets volume is ignored. $\mathrm{CC}$ differential equations concern mass conservation and mixture ratio differentiation, which is a rare approach similar to [4], a modelling reference without control purposes.

Kolcio et al [51] developed a procedure to define dynamic models of liquid-phase systems, such as LPRE, for control and monitoring purposes. Partial differ- ential equations of fluid flow through a control volume present the assumptions of quasi-one-dimensional, compressible and viscous fluid flow. Whenever the governing conservation equations (continuity, momentum and energy) render the model too complex, empirical steady state input-output maps are incorporated. These equations are then non-dimensionalised and this way a term expressing the speed of their dynamic response appears. Depending on its order of magnitude, transient behaviour can be neglected and hence model's order can be reduced. The same modelling procedure is applied to all fluid components, but a different discretisation is applied depending on the type of component. Discretisation is required to obtain nonlinear ODEs and reduce model's order, since spatial contributions are considered as linear. Individual component models, whose states consist in Mach numbers, pressures and temperatures, can be joined to obtain a global system model. Turbopumps are also considered, and present an empirical formulation. This modelling approach is said to be specially appropriate for simulating anomalies or faults, but no comments on control inputs or on any example of a global system model derivation are made.

The control modelling approach by YANG et al [52] can also be mentioned. A rocket engine is modelled in a nonlinear way as a feed-forward neural network made out of radial basis functions, adequate for real-time monitoring, diagnosis and control. LE GonIDEC 2017 [53] also employs a nonlinear artificial neural network representing the engine, although it is only used for estimation. Concretely, its static part is considered in the network, which is trained via databases and tests to provide correct mixture-ratio estimations.

The plant model by DAI AND RAY [36], in the same research group as LoRENzo et al [24] (NASA Lewis/Glenn Research Centre), was obtained by translating the typical thermo-fluid-dynamic partial differential equations of conservation to first-order ODE (ordinary differential equation) by means of standard lumped parameter methods. Twenty states, two inputs (oxidiser valves) and two measured variables were attained. Structural and damage models are explained in greater detail in other companion papers $[54,55]$. This consists in the only nonlinear model found, on which a control algorithm has been designed (even if it is in OL), as explained later in Section 4.

PÉREZ-Roca et al [56] presented a nonlinear LPRE statespace modelling approach aiming at filling this gap of LPRE CL control based on nonlinear models. The model is representative of the GG-cycle Vulcain engine, but the procedure can be extrapolated to other engines and cycles. The process to obtain that model 
adapted to the control formalism begun with a thermofluid-dynamic modelling phase based on the conservation equations on mass, momentum and energy and on turbopump-shaft dynamics. These typical thermodynamic equations are applied to each basic component of a rocket engine. Components are then joined to build a simulator of the engine, which satisfactorily predicts the start-up transient. Subsequently, the same system was translated into a symbolic model and physically reduced, so as to obtain the formal nonlinear differential equations as functions of states, inputs and engine parameters. States comprise two rotational speeds, four pressures, two temperatures and six mass flows. Some control inputs are continuous (valves angles) and others are discrete (igniter and starter), which renders the system hybrid.

\subsection{Sensors and actuators considerations}

Sensors. Many sensors are installed in LPRE, but their location and redundancy are usually limited by physical constraints or risk considerations. Thus, real engines and test benches often present slightly different sensor configurations. Important variables for [3] to be measured are the following. Measured states can be combustion temperatures, cavity pressures, turbopumps speed and some mass flows. Concerning control inputs, valve positions can be measured; and sometimes there are other physical parameters or quantities relevant to determine, such as fuel and oxidiser temperatures or vibrations. Classically, the sample rate is chosen in accordance with the measurement type and the application to supply (i.e. safety, monitoring or control).

For measuring valve position in terms of angles the rotary variable differential transformer (RVDT) is usually employed, while in terms of linear motion, the linear variable differential transformer is used (LVDT). Especially in reusable engines, vibrations should be monitored during operation so as to identify bearing wear or fault. Radial accelerometers placed on the pumps transmit to bandpass amplifiers which read the real-time signal. New bearing-wear sensors and real-time tracking filters are expected to furnish precise vibration measurements. According to [3], in order to mitigate the impact of random vibration, a narrow-band tracking filter is a good option since it measures synchronous and harmonic vibration.

Temperature sensors generally consist in thermocouples and in resistance temperature devices (RTD) [3]. Each RTD requires a bridge termination network with noise filtering and each thermocouple needs an additional gain. It is generally required that the sensors be robust and resistant to high temperatures and pressures, but the main $\mathrm{CC}$ temperature is usually too hot to be measured, and only GG or preburner temperatures are measured. This issue, together with the lack of some mass-flow measurements mentioned in the next paragraphs, can lead to partial observability, generally compensated by introducing estimators. Rotational speed sensors are generally of variable-reluctance type, comprising a permanent magnet and an independent pole piece surrounded by a coil winding of thin-filament magnet wire. These sensors can be used for control feedback but their main use is turbopump (TP) redlines monitoring.

The SSME presented 80 sensors collecting measurements at $50 \mathrm{~Hz}$ including the redundant ones [16]. Those related to the control loop performance were tripled and those used for limits monitoring were doubled. Chamber pressure sensors were used to compute thrust, as logical, and volumetric-flowmeters were used to compute mixture ratio, after correcting with density calculations based on pressure and temperature.

Regarding the recommended sensors in [25], indications on their time-response features are given. They may present two distinct response time-scales, a faster one for feedback and a slower one for the possible adaptive filters. For dynamic pressure measurements, piezoresistive or piezoelectric transducers are often used due to their high sensitivities and high natural frequencies, able to cover the large pressure range in LPRE.

In ArianeGroup's [57], the sensors required for their control loop are mentioned: flow-rate sensors are installed prior to the chamber, apart from the typical pressure sensor inside the chamber. A divider module, with protection against division by zero is used to compute the mixture ratio from the flow sensors. This is then sent as feedback, as well as chamber pressure measurement.

When dealing with test-bench control, ArianeGroup usually define mixture ratio at pump inlet, instead of the chamber-inlet one [17]. In this manner, the ratio between the pumped mass flows is established, attaining an expression of engine's global performance. This comes from the easier installation of flowmeters, typically of differential-pressure type (venturis and orifice plates), at pump inlets in test benches. But in actual engines in flight, most mass flows are normally not measured. Hence, estimators have to be used (different solutions, for instance neural networks [53]), which vary from one engine to another. As an example, the number of sensors in the Vinci test bench is: two chamber pressure sensors and twenty-seven sensors devoted to computing mass flow from volumetric flow, temperatures and pressures (with redundancies). The estimation 


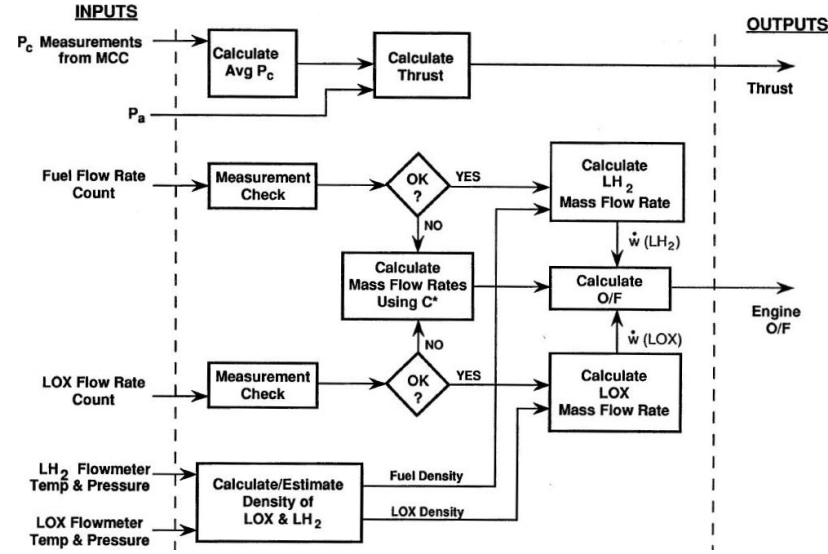

Figure 6: Mixture-ratio estimation and thrust calculation diagram by Nеметн et al 1991 [23], where $O / F$ stands for $M R$, $P_{c}$ for combustion pressure, MCC for main combustion chamber and $P_{a}$ for ambient pressure

diagram by [23] is schematised in fig. 6, in which mixture ratio is estimated and thrust is calculated.

Sensor dynamics in [29] are of first order, representing the HPT discharge temperature sensors. In [18], straingage sensors, modelled as second-order systems, are used to measure pressures and engine thrust on a test bench.

Actuators. The principal actuating devices in rocket engines, valves, can generally adjust propellant flow or activate a bypass duct. Their internal actuators varying their opening angle can make use of electric motors or of hydraulic or pneumatic power. As commented in [58], nowadays these servo-controlling actuators make use of sophisticated electronics in order to deliver fast actuation speeds which allow an effective control. The drawbacks of these tunable valves are large bandwidths and elevated energy consumption, forced by their internal servo-control loops. An alternative proposed in [58] is the use of bang-bang actuators not requiring expensive electronics. However, electrical actuators are gaining importance in valve-position control with respect to traditional pneumatic ones. The main reasons are that auxiliary helium-gas consumption and costs can be reduced and throttling efficiency is improved [59]. That is why the new hardware-in-the-loop (HIL) simulation platform by CNES and ArianeGroup [60] includes real valve-internal electric actuators. Since no real fluid lines are considered, the resisting torque on their hypothetical wet surface, equivalent to the real hydraulic one, is performed by another coupled actuator.

In [49] it is suggested to analyse the sensitivity functions relating mixture ratio and thrust with pressure drop and opening angles in control valves. The outcome of that analysis influences the selection of valve types (butterfly, shut-off, needle, ball, etc.), which must meet different kind of requirements, such as the characteristic relation between flow rate and pressure drop, actuation efforts, controllability, cost, weight, etc.

The SSME presented hydraulically-actuated valves, which in the event of a failure, were actuated by pneumatic elements rather than by the controller [16]. Reference [3] recommends that solenoids and drivers designs should include built-in fault detection checking voltage and/or current.

Actuator dynamics in [29] are defined by a servo motor with second-order dynamics, a first-order piston linkage and hysteresis (four states). Electrohydraulic servovalves of plug-type are used in [18].

Bypass-valves dynamics in [43] are modelled as a second-order system, whose gain depends on opening position (via a first-order polynomial).

Some examples of actuators highlighted by [25] to counter-act combustion instabilities consist in compression drivers adding acoustic energy at certain frequencies, flow injectors adding secondary mass flow, large valves modulating the total mass flow, mechanical devices altering boundary layers, fluidic devices adding momentum to the flow and special electrodes initiating current-stabilised electric discharges.

Other family of actuators present in LPRE are igniters, used to initiate combustion in chambers. In European GG cycles, they are typically of pyrotechnic type, but spark-based ones have also been used elsewhere. They are generally not considered in control models since their effect consists in a discrete event only taking place during the start-up or re-ignition transients. Apart from the fact that not many transient control studies [23] have been carried out, this discrete actuator is not normally considered as a control input, mainly because the system would become hybrid. It was considered as an input in [56], where it can modify engine dynamics, but its relevance in control strategies remains a matter of study.

\subsection{Analysis}

Concerning the stability analysis, as mentioned in [2], rocket engines operation tends to be naturally stable, mainly because the liquid flow system counter-acts disturbances and off-design behaviour. The system naturally tends to regulate itself. Nevertheless, some internal natural resonances, mostly related to TP rotation, may present frequencies that could destabilise the system. Some stability-regions computation methods are proposed in [38] and [39]: the Mikhailov, Hermite-Biehler 
and Routh-Hurwitz criteria. Indeed, these authors point to the need for checking whether the typical rocketengine transient phenomena interact with system's natural frequencies leading to instability. The main physical parameters influencing these low frequency couplings are, according to [39], pressure drop in the injector (connecting chamber and feed-lines oscillations), evaporation delay (to minimise) and combustion-chamber characteristic time or residence time. After joining combustion-chamber and injector equations in the frequency domain, an expression with these three main parameters can be obtained.

The Mikhailov criterion requires the construction of a frequency plot, where stability limits can be drawn. However, this method is sometimes cumbersome. The Hermite-Biehler theorem (Interlacing theorem) ensures necessary and sufficient conditions for the Hurwitz stability of a real polynomial.

The Routh-Hurwitz criterion, used in [38], can also be employed to compute the stability zones. It represents a mixture of both previous methods, since certain value ranges are selected for each parameter and then characteristic equations are solved. In all cases it is concluded that the system is stable within a wide enough region.

Both simulations and tests in [41] show the presence of reverse reactions, under- and overshooting in the transient of GG outlet pressure. Those initial reverse reactions, common in rocket engines, correspond to the non-minimum phase behaviour in the control terminology. This is mathematically expressed by the presence of a right-hand-plane zero in the transfer function, between valve area and outlet pressure in that case.

Regarding the essential controllability and observability analysis, NEMETH et al [23] describe the different behaviour stages of a LPRE during its start-up transient. Those authors clearly identify four stages of controllability and observability, schematised in fig. 7. The first stage comprises all discrete events (ignitions and valve openings), from the activation of the start command until the engine can be considered as a fully continuous system. The second stage consists in the transition phase between the end of discrete events and the start of CL control, where the main thrust buildup occurs. In the SSME case, stage 3 starts with combustion pressure CL control and the fourth one begins with mixture-ratio CL control. It is highlighted that the stages on which control should be improved the most are the first two, where the most damaging transient phenomena may occur. The SSME is said to be hardly observable or controllable during stage 1 , as well as to contain model-plant mismatch. Different control alternatives were tested for controlling the start transient in

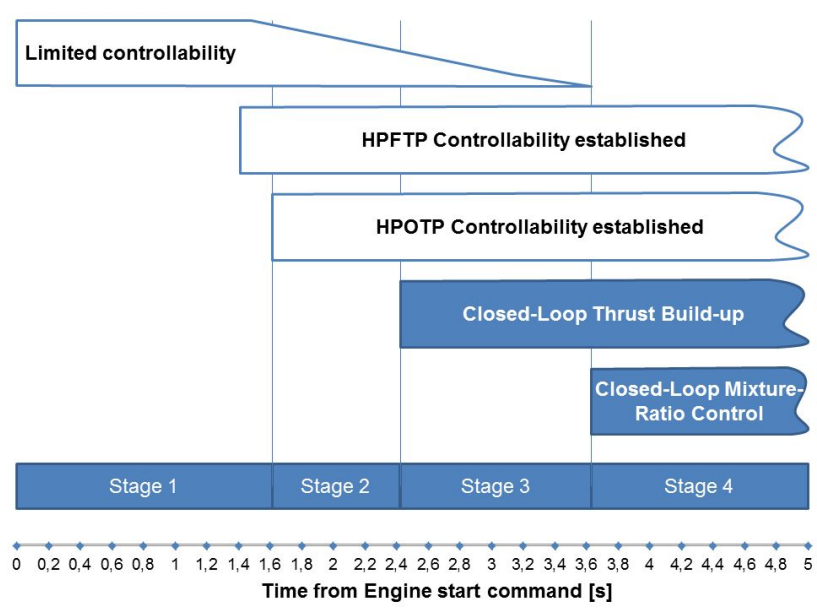

Figure 7: SSME start-up stages of controllability [23], HPFTP and HPOTP are high-pressure fuel and oxidiser TP

[23], but those authors did not manage to obtain positive results due to these observability and controllability issues. In fact, they had to assume that these properties were met, although in reality it is very difficult to measure some quantities during the first stage of the transient, especially for oxygen. For instance, designing a flowmeter that detects small hydrogen flows at low pressures, which are very different from steady-state ones, is not a trivial task. In addition, those reduced flows at the early phases limit controllability. However, it would seem somewhat possible to measure and control on the hydrogen side because it remains monophasic (supercritical), while it seems impossible to those authors on the two-phase oxygen side. TP speeds are accurately measurable during start-up but are hardly controllable before their respective preburner is filled, which allows the management of the energy transmitted to the turbine. All these constraints led those authors to reject CL control during the discrete-events stage of start-up as a feasible approach. An ad-hoc approach expressed through an influence model was also tested, relating the deviations in observable states to the necessary valve opening counteraction. Nevertheless, no action is carried out on unobservable states, which in the end can result in greater damage after anomalies. Due to these negative results, [23] proposed to modify SSME configuration to allow observability and controllability during the discrete-event phase. For instance, lines could already be primed prior to start-up. 


\section{Review of control methods}

With regard to the actual control techniques employed in the reviewed references, they can be classed in diverse categories: open-loop, conventional CL, nonlinear, robust, hybrid and reconfigurable control approaches.

\subsection{Open-loop control}

Open loops are generally preferred due to their simplicity. Since conventional rocket engines are naturally stable in flight, if no high performance levels are expected, OL consists in a valid option. However, if high performance is sought or if the application is special, it may be a limited method since it is normally impossible for the input to know the transient response of the system. Even if there is a constant valve opening, the external conditions may alter the operating point.

An OL strategy applied to combustion [25] contains a controller accompanied by an actuator powerful enough to modify the combustion process. Common control actions are oscillatory inputs, which have achieved instability suppression, combustion enhancement and emission reduction.

Another OL (feed-forward) control algorithm within the project of LEC of SSME was developed by DAI AND RAY [36]. This approach, one of the most relevant in this survey, consists in an optimal policy to control the rocket engine along a nominal trajectory during its throttling transients. Off-line optimisation is performed on a plant model taking into account structural and damage dynamics as well as constraints of fatigue and creep damage, so as to extend critical components' life.

The outcome of the algorithm is an optimal control sequence with two functions: making a trade-off between performance and damage and identifying possible conflicting requirements posed by damage mitigation. This control sequence driving the system from an initial equilibrium state (186bar) to another one at a higher pressure (207bar), considers a quadratic cost functional: the square of the weighted sum of $L_{2}$-norms of states, outputs, control action (only two preburner oxidiser valves), deviations from final state and damage states derivatives. Nonlinear Programming (NLP) was used to optimise this cost functional of plant's performance without violating damage rate and accumulation constraints. The most important output to the authors is mixture ratio, which must be kept constant during the $300 \mathrm{~ms}$-long operating-point shift. Time steps are gradually incremented from $\Delta t_{1}=3 \mathrm{~ms}$ in order to represent better the initial quicker dynamics with a Runge-Kutta scheme, obtaining a total number of 37 steps. Results were very positive and pointed to a possible extension of main thrust chamber's life due to the imposition of those constraints.

KIFORENKo AND KhaRITONov [61] developed an off-line optimal control strategy for controlling the thrust of a LPRE. The control problem is considered from the perspective of the whole launcher vehicle, whose thrust needs to be optimised. This is indeed one of the crucial problems of rocket flight mechanics. Thrust is maximal when nozzle's outflow velocity is so, reached at an optimal mixture ratio, dependent on engine's parameters and assumed constant. A simple model of engine's global behaviour is chosen: an algebraic expression relating thrust to injected propellant mass flows into the main chamber links the controlled variable to controls. Differential equations consist in the general equations of motion of a launcher vehicle (centre of mass). These involve propellant mass consumption, dependent on mass flow rates; and acceleration, dependent on thrust. Rocket's full mass evolution, including engine-system mass, is considered in that relation between acceleration and thrust.

Control actions consist in both main propellant mass flows, on which some constraints are imposed: a minimum and a maximum mixture ratio. Chamber pressure, also related to thrust via an algebraic formula, must not exceed an upper value. The admissible domain of controls is set according to those constraints. Fuel mass flow is expressed as a function of oxidiser mass flow via second-order polynomials. This way, only one control variable can be considered. The lower and upper value of mixture ratio multiplied by oxidiser mass flow are logically straight boundaries in the domain.

The optimal-control objective is reaching a maximum velocity within the allowable control domain, expressed in terms oxidiser mass flow. An indirect method via Pontryagin's optimality principle is employed, where the Hamiltonian function contains three adjoint functions multiplying acceleration, fuel mass flow and oxidiser mass flow respectively, all expressed as functions of the latter. Equations are rendered non-dimensional. At the initial instant, no optimal solution can be attained within the allowable domain, but control increases during operation and optimality conditions (maximum of Hamiltonian function) are met. Besides, only one control meets those conditions at each time instant in the appropriate intervals. Better results than traditional control are attained, but engine's internal transient behaviour is neglected. 


\subsection{Conventional CL control}

The first step to enhance the robustness and performance of an OL is to add sensors, desirably to measure pressure or temperature fluctuations [25], and close the loop with a feedback. It is convenient that the frequency response of the closed-loop sensor be higher than the operating frequency of the controller and actuator.

By implementing CL, the number of engine tests can be reduced, a steady state can be maintained and the overall launcher trajectory can be better predicted. Consequently, one can be less conservative in terms of propellant mass.

The analogue approach by OtTo AND Flage from NASA 1959 [18] considers a $3 \times 2$ MIMO system (chamber pressure, fuel flow and oxidiser flow related to two main valves). Their main objective was the classical one in control: attaining zero voltage difference between measurements and a reference. The MIMO is decoupled into three SISOs. The oxidiser control valve is in charge of controlling mixture ratio (first SISO), while the fuel control valve controls either the fuel flow itself or chamber pressure (two alternative SISOs). Indeed, the fuelflow loop (based on fuel-flow feedback) is only active during the fuel-lead phase of the start-up, when there is no oxygen. Then, the fuel control valve switches over to participate in the chamber-pressure loop, and the oxidiser-flow loop is activated, as it can be seen in fig. 8. It is mentioned that the opposite decoupling is also possible, but less safe. In order to obtain propellantflow measurements, pressure drop in each feed line is measured (with Venturis) and compared to references. Chamber pressure is also measured. So as to meet the maximum mixture-ratio requirement, the speed of the pressure loop was deliberately reduced. This way, the oxidiser valve could adapt quickly to changes in fuel flow and hence avoid ratio peaks. Controllers in the previous study are of PI type with small gain (less than 1), also during start-up. Step changes in mixture ratio reference are well tracked, with $15 \%$ overshoot. These setpoint switches last around $1.5 \mathrm{~s}$. Delays during start-up, especially in chamber pressure rise after valve opening, reduce control system's accuracy. Besides, a constant pressure reference is provided from the beginning, resulting in the aforementioned overshoot.

A simple and robust method to regulate a rocket engine with at least one combustion chamber is presented in ArianeGroup's work by KLEIN et al [57]. It is particularly applicable to expander cycles but also extendable to GG ones. The opening command to chamber feed valves is computed in OL, coming from an external order. The command to turbines' regulators device (bypass valves) is calculated in CL. The overall perfor- mance is satisfactory while keeping computational demand low.

A tracking filter (first or second order) is applied to the external reference of chamber pressure and mixture ratio, coming from predefined profiles, ground order or calculation by the electronic control unit according to flight data. With this filtered command, valve orders can be computed as fourth-order polynomial functions of the ratio between the filtered chamber pressure command and its maximum value allowed. But other alternatives are possible, such as artificial neural networks. The controller consists in a dual PI corrector, with a higher cut-off frequency than the tracking filter.

The previous reference is one of the multiple studies which ArianeGroup have carried out in the last decade concerning the control of expander-cycle engines [58, 62, 53]. In reference [58], combustion chamber pressure and mixture ratio are considered measured and are adjusted according to set-points, by means of a bang-bang control strategy applied to slow actuators. This way, nonlinearities are said to be introduced in the control strategy for avoiding over-demand on the electric motor. A minimum threshold on the set-point tracking error is set too. The continuous controller itself can simply be an integral action. However, the command sent to actuators, which consists in power supply pulses, is quantised (discretised) and presents variable durations.

In [62], the same control goal is targeted, but it is solved differently while complying with operating limits. Firstly, the set-point signal is again filtered via a first-order filter. Then, a multivariable command with a predictive internal model is employed. This approach calculates the control necessary to reach a future objective while knowing a prediction of system behaviour within a given horizon. However, this linear offline controller cannot be classified under the standard optimisation-based predictive control methods, such as MPC (Model Predictive Control). In order to comply with engine limits, the control module tunes a control gain factor according to the lower of the differences between measured shafts rotation speeds and their operating limits. Measurements of that variable and of mass flows and chamber pressure, as well as the filtered setpoint, are provided to the controller.

Reference [53] goes one step further and considers that mass flow measurements and hence mixture ratio measurements are not available. They are estimated from valve control signals and measured pressure. Indeed, as stated in Section 3.2, it is usually costly to insert massflowmeters in engine's lines. The engine is mainly controlled according to chamber-pressure reference, and 


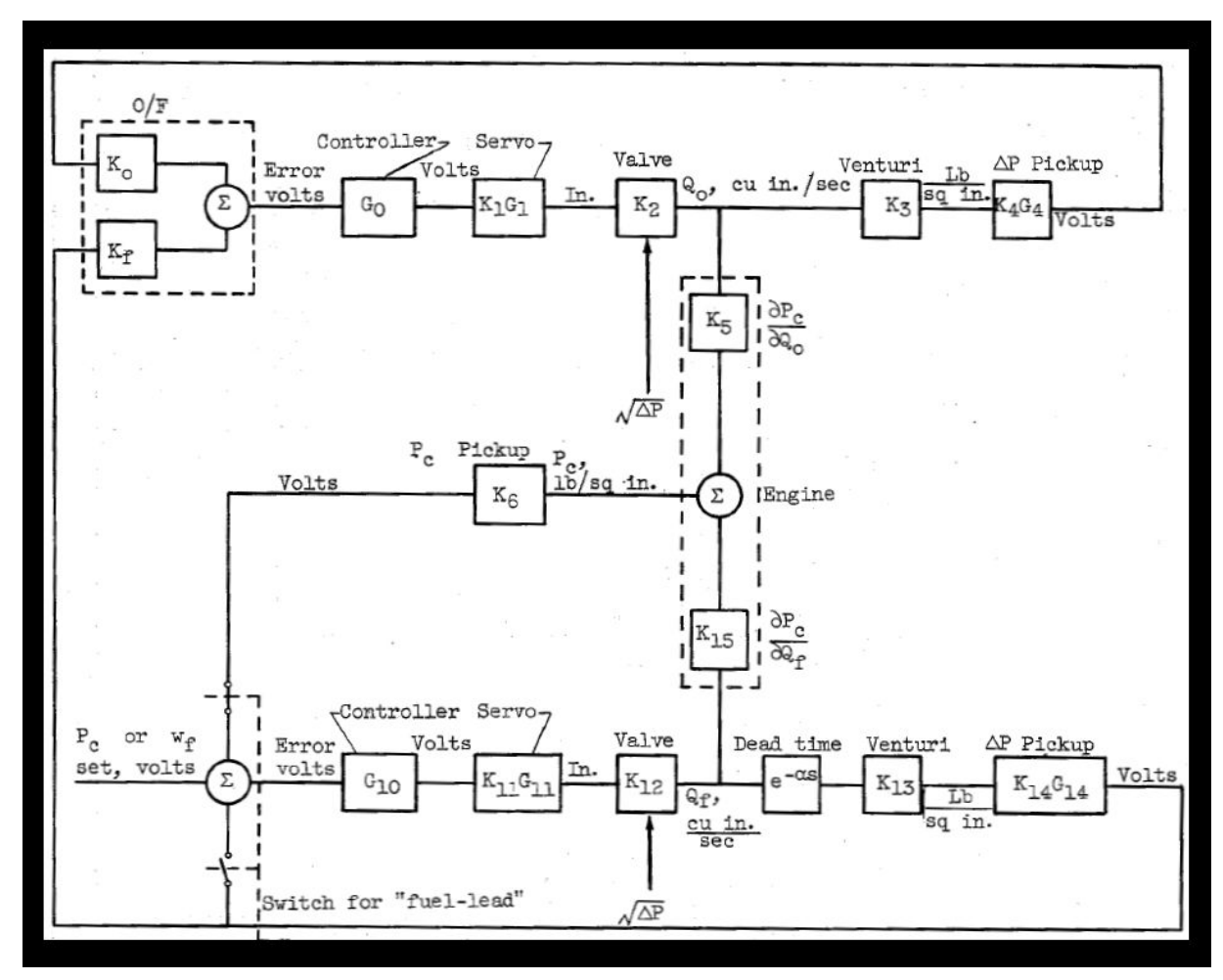

Figure 8: Control system schematic by Otтo and FlaGe [18]

then valves commands variations are adapted to ensure a desired mixture ratio.

In the state-space framework by [50] a particular variation of injected flow is considered, by means of a springpintle system whose position is altered by two valves. The feedback signal is the measured combustion pressure multiplied by a gain. That gain is affected by a combination of effects: valve's displacement, orifice diameter, pressure difference and pulse width. They concluded that the three main control parameters which influence the dynamic response time and control precision of such an engine are: pulse width, the operating frequency of solenoid valves and the deviation from their critical operating points. Valve's frequency is the main contributor to the sampling frequency of the whole control circuit. It represents controller's ability to track the chamber-pressure reference. Its increase reduces overshoot. These parameters are tuned so as to obtain the most convenient engine behaviour. All in all, they include a term in the definition of valves' mass flow related to these parameters, utilising an empirical correlation to characteristic times equivalent to a first-order system.

A bipropellant variable-thrust rocket engine is also con- trolled by means of solenoid valves and variable-area injectors in the work of ZHou [42]. The control system comprises a control circuit, two solenoid valves, two variable-section injectors and the thrust chamber. The control circuit contains operational amplifiers that receive the reference voltage signal and combustionchamber pressure feedback signal, and output a deviation signal. Control action is exerted by valves, that indirectly let injectors undergo section variations according to pressure, by means of springs. This type of valves are pulse operational. Thus, control gain depends on a selected pulse width divided by the error voltage signal. Pulse frequency is set between 50 and $100 \mathrm{~Hz}$. The compact transfer function modelled can be used to demonstrate stability for a given combination of parameters and control gain. Some issues regarding steady-state error at high thrust are mentioned.

The most recent publications dealing with CL control of LPRE come from the Japanese space agency JAXA. The $L E-X$ engine by this agency is designed with high reliability and low-cost objectives and presents decoupled automatic control of mixture ratio and thrust by means of electric-actuator valves, enabling a smooth throttling, as presented by Sunakawa et al [63]. These valves are: 
thrust control valve (TCV), controlling thrust via the flow rate of turbine output gas; main oxidiser valve (MOV), controlling mixture ratio via the oxidiser pressure at chamber inlet; and main fuel valve (MFV), employed during throttling so as to maintain turbine inlet temperature at reasonable levels.

The control strategy was designed thanks to subscale valve tests and transient simulation. A two-degreeof-freedom control is applied: an estimation $P^{\prime}(s)$ of the actual plant $P(s)$ is made. A non-described controller, whose denominator is $P^{\prime}(s)$, is designed to determine the output transient response. However, since $P^{\prime}(s)$ is not perfect, a PI controller is included to correct the error. Ramp and step responses were tested at the three throttle levels $(0 \%, 60 \%$ and $100 \%)$. Simulations presented no overshoot in thrust or mixture ratio but the chamber coolant temperature simulation at ramp response had it to an important extent, which may represent a big heat stress source. Thus, the step command was chosen for control. In order to verify and refine the control method, subscale valve tests were carried out with gaseous nitrogen.

The control algorithm for JAXA's current designs of reusable expander-bleed engines, by KAI et al [9], consists in a combination of simple feed-forward and feedback controls which achieves thrust tracking at steadystate. Three electrically-actuated ball-type valves are used for control. All three are of continuous nature and their effects on the controlled quantities are again decoupled in three SISO loops: on thrust, mixture ratio, and turbine inlet temperature, as in [63]. These three controllers present feed-forward at $100 \mathrm{~Hz}$ according to a predefined valve position table for each level of thrust command. All three also receive feedback measurements of pressure, temperature and flow rates. The thrust loop contains a PI controller at $25 \mathrm{~Hz}$ while mixture ratio and turbine inlet temperature only present threshold feedback control at $0.5 \mathrm{~Hz}$. PI parameters were tuned according to step and frequency response test results.

Results after the start-up phase of the engine are positive, although with some overshoot. A constant steadystate thrust command is fed from the beginning. Those authors affirm that the engine can throttle between $21 \%$ and $109 \%$ at test bench with their controller, which is a major accomplishment in the current context seeing the high technical difficulty of down-throttling.

\subsection{Nonlinear control}

The only reference considering nonlinear techniques in CL is the mixed linear-nonlinear approach in [31], where two main loops are defined in the control system: an inner one for the performance controller linked to the linearised plant and an outer one for the nonlinear damage controller. This controller is designed on the combination of the performance controller and the plant model. Its main elements consist in a structural model for load conditions, a time-domain damage model, determining the damage rate based on the load estimations; and a damage controller, mitigating damage rate and accumulation at critical conditions, normally in transients.

On the inner loop, an $H_{\infty}$ controller (optimal $L_{2}$ norm) is tuned. Its performance weights penalise outputs' tracking errors and control signal weights penalise valve motion, in order to minimise valve wear and to avoid large oscillations in the feedback control signal leading to valve saturation. The initial order of the controller is fifteen, but it could be reduced to five.

Damage modelling is carried out in continuous time and represents fatigue damage in the turbine blades, assumed to happen due to tensile loads and not to temperature. The outer control loop consists in a nested connection of the three elements mentioned before: structural estimator, nonlinear fatigue model and a linear dynamic filter as damage controller. The parameters of the latter are identified off-line by minimising a cost functional based on nonlinear optimisation, through Sequential Quadratic Programming (SQP). This functional is tuned first at a certain simulation, a representative pressure ramp-up, and comprises the effects of both reference tracking performance and blade damage. Interaction between the damage and performance controllers is mitigated by introducing the high-performance requirements in the cost functional and by the fact that both loops present different frequencies (higher for the outer one).

Results point to a slower pressure response with less overshoot due to the inclusion of the damage controller. Mixture ratio deviates too much during the transient but reaches the desired steady-state value. Damage rate in the hydrogen turbine is somewhat excessive, and checked to be higher in a more demanding simulation. But without the controller, results are absolutely not tolerable since damage in blades quickly gains two orders of magnitude during start-up, which reduces engine's life dramatically.

\subsection{Robust control}

Robust control is another important field of study in this application with some uncertain parameters, varying during engine execution or from run to run. As observed by BARs et al [64], current innovative robust 
studies in general deal with probabilistic robustness. Concretely, randomised algorithms can bring about a reduction in the computational complexity of classical robust algorithms and in the conservativeness of $H_{\infty}$ techniques. However, as explained in the next paragraphs, only the latter have been applied to LPRE, as well as KHARITONOv's theorem.

Robust control theory is applied to linear models of LPRE in the work of SANTANA et al [37], considering uncertainties in the plant coefficients. Robust stability is ensured by means of the generalised Kharitonov's theorem (based on [65]) and it is concluded that robust control is capable of estimating the range of the required stabilising coefficients.

In fact, according to [37], conventional numerical methods for analysis are not adequate for uncertain models, requiring long computational times. Transfer functions with uncertain parameters would consist in an easier solution. KHARITONOv's theorem involves interval polynomials $p(s)$, whose coefficients are defined as intervals (assumed independent). Every polynomial in the family of $p(s)$ is Hurwitz stable if its four extreme polynomials are so. These extreme or KHARITONov polynomials present different combinations of extreme coefficient values. The application of this theorem to the characteristic polynomial of a plant with uncertain parameters like a rocket engine renders a necessary and sufficient condition for stability analysis.

Two uncertain parameters are selected for the robustness study in [37]: combustion chamber's time delay and time constant. These have the highest influence on the low-frequency combustion instabilities $(50-1000 \mathrm{~Hz})$, generated by the interaction between the feed system and the combustion process. Hence, this frequency range was selected for the analysis. The delay can be estimated by the Crocco's relation and the time constant represents the time that the gas remains in the chamber. Bode and Nyquist envelopes were computed by means of the PST and the RPC $M A T L A B \otimes$ toolboxes, confirming stability in the selected frequency range. The robust step response (in PST) demonstrated acceptable dynamic performance at the chosen parameter intervals $([1,5] \mathrm{ms}$ for the delay and $[2,5] m s$ for the constant).

The $H_{\infty}$ robust-control approach by LE FUR et al [43] enables to throttle an expander-cycle rocket engine between 50 to $110 \%$ of nominal thrust in simulations, with a mixture ratio varying between 5.5 and 6.5 .

Simulation at different operating points (low and high chamber pressures) gives very dissimilar behaviours in the outputs, which leads those authors to affirm that a unique controller is difficult to synthesise. For instance, the solution for a given point destabilises the system at another regime. Hence, three different $H_{\infty}$ controllers are synthesised at three distinct operating points. Loop shaping is performed via pre and post-compensation. Performance is set as a low-frequency constraint and robustness as a high-frequency one, as usual in this kind of techniques. However, loop shaping does not guarantee CL stability; the gain slope in the vicinity of the cut-off frequency can become too steep. In the $H_{\infty}$ framework by [43], this is corrected by means of a PID-based controller, that contains both a phase-lead controller to enlarge robustness margins by increasing the phase and avoiding high gain slopes, and an integrator to cancel the static error.

Several criteria are used to determine the controller and the weights of compensators: stability, inputperturbation rejection, steady-state error, actuators demand and bandwidth. Each one presents a different $H_{\infty}$-norm minimisation objective. Results show that it is more convenient to put the controller in the feedback loop so as to reduce overshoot and actuators saturation. Those authors propose gain scheduling for future steps, and affirm that a unique $H_{\infty}$ controller would be feasible if some modifications were carried out on the engine, so as to have less different operating points.

The compromise between performance and robustness is again mentioned in the report by SAUDEMONT AND LE GoNIDEC [44], who also developed a robust $H_{\infty}$ control, this time on the Vulcain engine. Basically, greater gains are tuned at low frequencies to improve performance (settling time specification) and low gains are selected at higher ones to remain stable and robust.

It is a fact that the behaviour of the rocket engine varies as a function of the operating point (thrust and mixture ratio). Therefore, the system here consists in a Linear Parameter-Varying (LPV) system, considering that some parameters vary with operation changes. Those uncertain parameters are expressed here by means of the Linear Fractional Transformation (LFT), used in the $H_{\infty}$ synthesis. This expression of uncertainty makes use of parameters mean values and maximum amplitudes, multiplying the so-called uncertainty variables, defined between -1 and 1 . The matrix model of this engine presents three inputs (GG input valves VGH and VGO and turbines flow distribution valve VGC) and three outputs (GG temperature, chamber pressure and global mixture ratio). The three output sensors, represented by first-order transfer functions with uncertain time constants, are also added to the model. A delay is also joined to their outlet, expressing the processing time required by the calculator, uncertain too. All these elements are expressed in superior LFT and linearly 
joined in a single matrix. For this sake, engine's matrix had to be decoupled by means of the structured uncertainty matrix. Mean values and maximum amplitudes are considered fixed. Hence, the resulting system is only dependent on the uncertainty matrix (a function of uncertainty variables), which is of dimension nine.

Regarding $H_{\infty}$ design choices, the post-corrector or post-weight is chosen as the inverse of system's nominal matrix (without deviations), to compensate the static gain introduced by that matrix. The pre-weight is tuned as a set of integrators with different gains to ensure a bandwidth of $2 \mathrm{rad} / \mathrm{s}$. The controller is obtained via the normalised coprime factorisation synthesis, available in the $\mu$-synthesis MATLAB® toolbox. It is based on the problem of robust stabilisation of coprime factorisations and generally computes a high-order controller (eighth in this case). With this configuration the system is able to reach the reference signal and reject perturbations acceptably well.

\subsection{Hybrid control}

Systems consisting of both discrete and continuous characteristics at the same time are called hybrid systems. The basic phenomena in typical control problems are naturally continuous, normally defined by smooth functions. But if at some points, abrupt variations related to behaviour changes appear, discrete variables may come into play. This way, the different physical modes of the system can be modelled, usually in the form of piecewise continuous or affine systems. Other types of discrete features can be discrete outputs (sensors), inputs (actuators) and discrete-event controllers. An example of discrete or discontinuous control can be gain scheduling. Hierarchical control structures such as the ICS proposed by [24] can be very appropriate for models with large uncertainties, noise and disturbances, according to [64]. These structures might comprise a set of controllers, estimators and generators, forcing the need for a switching logic to decide which ones are executed. Indeed, the adequate controller is selected according to some rules defined in the switching logic, related to parameter uncertainties ranges. This logic determines in the end the global stability and performance of the closed-loop, transforming the system into a hybrid one due to its discrete dynamics. For [64], these schemes are an attractive alternative to typical continuously-tuned adaptive controllers because they reduce conservatism and enhance stabilisation and control performance, especially during transients. However, switching strategies are not the only hybrid approach; hybrid control is still an evolving field.
Only one reference concerning a subtype of hybrid control applied to an LPRE aspect has been identified. ZHENG et al [26] employed a variable-structure control for stabilising combustion in LPRE, which can be considered as an unstable time-delay system. These authors affirm, that if this system is stabilised by linear state feedback, robustness against variations is not guaranteed. It is shown that a switching functional should be used in variable-structure controllers for systems with state or control-inputs delays. Basically, stable sliding modes are derived, in which the delayed system is transformed into a non-delayed one thanks to characteristic matrices.

The Crocco monopropellant combustion model [46] is considered in that previous work, where two parameters can vary: reduced time lag and pressure's exponent (pressure dependence of combustion), difficult to measure. The former is the ratio between time lag and gas residence time in steady operations. The control variable taken, supposing a unique, regulated injected flow with no concrete valves to control, is the ratio between the pressure drop in the line before the injector and two times the drop in the injector. Results point to stability and better robustness results than with the linear feedback.

In a posterior paper, ZHENG AND FRANK [27] prove the robust stability conditions on general uncertain distributed delay-system and apply it to the same combustion model. Another stabilisation method based on LMI (Linear Matrix Inequality) is tested, said to be more efficient and not to require parameter tuning. This way, allowable parameter-varying ranges can be determined. Furthermore, some elements related to hybrid control, like switching, may be extracted from the SSME reconfigurable control approach by MusGrave et al [29], classified in the 4.6 category, but a concrete hybrid framework applied to LPRE systems (not only combustion) is missing.

\subsection{Reconfigurable control}

In general, conventional feedback control engineering may not be sufficient for modern complex systems in terms of performance. New strategies which tolerate failures while keeping stability and performance features are arising. According to ZhaNG AND JiANG [66], thanks to fault-tolerant control systems (FTCS) reliability and availability can be increased, adapting to component malfunctions automatically. These systems involve Fault Detection and Diagnosis (FDD) and/or Fault Detection and Isolation (FDI) mechanisms. Research on these approaches was motivated by the world of civil aviation, with the aim of providing self-repairing 
capability for performing a safe landing. But nowadays it covers a wide range of applications, such as in aerospace, nuclear power, manufacturing, etc. Owing to the complexity to the problem, FDD and Reconfigurable Control (RC) have historically been studied separately. That is the reason why some techniques for the former do not match the ones for the latter, since it is assumed that the counter-part is perfect. In this review only the $\mathrm{RC}$ part is covered. The article by $\mathrm{Wu}$ [67] is a good survey of LPRE health monitoring.

Traditionally, reconfigurable control has not been systematically used in propulsion systems, since not many engines contain redundant actuators. Instead, these are designed with a high degree of reliability. Nevertheless, in rocket engines, a fault in a main valve could imply a catastrophic failure. Reliability is a key aspect in reusable systems, and hence the Health Monitoring System (HMS) plays a leading role in the global system design. This system should diagnose faults difficult to detect, owing to uncertainties or sensor noise. As pointed out in [3], the interface engine-vehicle includes not only commands like start, stop and thrust-level modifications, but also health-monitoring data, critical to attain the required redundancy level to accomplish the mission objective.

MARcos et al [68] present an architecture allowing the interaction between HMS and future control systems in LPRE, in the frame of the Future Launcher Preparatory Programme by ESA (2012). The tasks of diagnosis, prognosis and decision on the HMS side, and of management, reconfiguration and sequencing on the control side, are interrelated. The criticality of this interaction component is deemed as high as the one of HMS alone, and seems necessary for ensuring the development of reliable and robust fault-tolerant health-management systems. HMS information and engine status are managed in order to feed the controller with all abnormal behaviours. In fault cases, a gentle performance degradation (for instance a modification of mixture-ratio reference) could be attained with this architecture, instead of a brusque engine shutdown. For this sake, those authors envisage to use control techniques that allow fault accommodation or reconfiguration. Sequence reconfiguration via optimisation and engine parameters reestimation are highlighted among others.

It is relevant to comment again on the work by MusGRAVE et al [29]. Their reconfigurable controller comprises a command generator (synthesising the reference commands), several linear control designs and control blending. The valve fault accommodation process is a hybrid approach using gain scheduling and mode switching. The higher the number of accommodatable fault modes which the nominal robust controller cannot address, the higher the number of linear control alternatives. The authors consider that the nominal design cannot deal with the freezing of the FPOV, responsible for keeping a constant mixture ratio during throttling. In that event, the objective of the controller is to decouple $M R$ from $p_{c}$ using the remaining valves.

That main controller is synthesised using a robust method applicable to servo-compensators (LQG/LTR). This robust technique, explained in an earlier paper by MusGrave [69], is capable of attaining good trajectory tracking and robustness to unmodelled dynamics and disturbances. However, it requires plenty of sensors for that purpose, and a trade-off has to be done between robustness and noise rejection. But this multivariable servo design is proven to be adequate for the SSME, having a stable open loop. A linear time-invariant system is considered. States are estimated via measurements and inputs using a Kalman-Bucy filter. The accommodation controller is obtained by eliminating the column related to the faulty valve and keeping the same dimensions for the gains. This design maintains safe execution over some degrees of degradation at an acceptable performance without gain scheduling.

Both the nominal controller and the linear alternatives (PI) are run in parallel during some time so as to induce a smooth transition. That transition duration is determined by the blending rate, $2 \mathrm{~Hz}$ in that paper. The engine level coordinator is in charge of accomplishing $M R$ and $F$ requirements as close as possible while keeping away from engine shutdown. The authors have defined a correlation for this sake, relating the maximum thrust possible for a certain position of a frozen FPOV without falling into disturbing $M R$-deviations. Mixture ratio is kept to 6.01.

The nominal transient demonstrates excellent tracking, although some degradation after the FPOV fault can be seen during accommodation. The maximum thrust is recomputed continuously as the MBFD (Model-based fault detection) scheme estimates the valve position at a high accuracy. However, there is a trade-off between the speed of convergence of the scheme and the need for quickly detecting an actuator fault. This interdependency results in some position estimate degradation (around 3.5\%). A proposed solution may be delaying the thrust computation based on the valve position until the algorithm converges.

Another fault-tolerant strategy is carried out by SAROTTE et al [45] for the cooling circuit of a cryogeniccombustion test bench. This test bench, Mascotte by CNES/ONERA, was developed so as to investigate heat transfer in combustion chambers and jet separation in 
nozzles in realistic conditions comparable to the Vulcain 2 engine. In that paper, a FDI scheme is designed for detecting and estimating actuator faults in the subsystem in the presence of disturbances, via unknown-input observers and cumulative-sum algorithms. The goal of the fault-tolerant reconfiguration control is to attain steadystate tracking while compensating the estimated fault and thereby maintaining system stability.

For this sake, a transient nonlinear state-space model of the cooling circuit was derived, containing pressures and mass flows and assuming measurements of some of them.

The control law, defined after linearising the system around the nominal steady state, contains two main terms: one for compensating the fault, whose magnitude is estimated in the FDI part; and a second term consisting in the reconfiguration element. The gain associated to the latter is chosen so as to stabilise the faulty system by means of a linear-quadratic regulator (LQR). This controller is hence proposed for an equivalent system where the unknown input mass flow is formulated as a function of the known state and inputs. This law was successfully validated in representative simulations.

Reconfigurable sequences. Generally, rocket engines do not readapt their start-up or shutdown sequences as a function of their thermodynamic state; the same preprogrammed one is executed. The engineering novelty presented by LE GonIDEC in ArianeGroup [20] enables the engine to correct those sequences whenever there are variations in its structural or system characteristics, in its thermodynamic state or in the environment. This calculation method selects the instants at which the different operations are carried out before the sequence starts. Computations are concretely performed right after each start or stop.

Those instants are optimised after modelling engine behaviour and including criteria for proper operation regarding the different discrete operations, for start-up and shutdown. The thermodynamic variables taken into account are regenerative circuit's initial temperature, heating coefficient (temperature difference outlet-inlet) and head loss (pressure difference outlet-inlet), since the application example consists in an expander cycle. Valve cross sections and opening durations are taken into account as dimensional parameters. Criteria for proper engine operation concern TP rotation speeds and accelerations (reversal too) and mixture ratio.

In order to calculate the starting cues or event instants, two variants are proposed. For both of them, a system of matrix equations relating the previous variables and the event vector is established. Concretely, the crite- rion is the dependent-variable vector, the actions are the unknowns and the effect of dimensional and thermodynamic variables consists in the independent term. The LS method is the first possibility to be applied to that system, with a weighting factor concerning the criticality level of each criterion. The alternative method consists in developing a predictive module capable of foreseeing the proper operation criteria depending on the thermodynamic and dimensional parameters. Then, a fuzzy-logic module determines the action vector with that prediction.

Results show that similar chamber-pressure profiles are attained when starting from different initial temperatures. However, the build-up takes a little longer.

LPRE-FTCS test bench. CNES and ArianeGroup have developed a HIL simulation platform that can include real actuators and controller hardware [60] (RoMET et $a l$ ). It is called ISFM (from French, Engine Functional Simulation Platform) and is intended to allow the testing of control strategies with a certain link to real equipment. Adaptation to plenty of scenarios is possible, putting the focus on realistic failure cases to test FDI and RC algorithms. Qualification was performed on a real-time model of the Vinci engine, but other engines demonstrators are envisaged, such as for Prometheus. The real-time models used come from more complex ones on which a reduction analysis has been performed, including physics simplification.

\section{Summary and discussion}

Throughout the previous sections, it has become clear that LPRE control involves many considerations, but is generally accomplished by controlling thrust (or combustion-chamber pressure) and propellants mixture ratio (either the global ratio or chamber's one) by adjusting the opening angle of a set of dominant valves while considering several constraints. Apart from these main variables to control, which are traditionally decoupled in two loops, there is a series of secondary loops that fulfil auxiliary tasks, also necessary for the correct operation of the engine (summarised in Section 2.1). Each engine and cycle presents its own peculiarities, concerning time constants, internal dependencies and sensitivities, which hinders the reuse of controllers among different devices.

The first and most important question to answer for conceiving a control algorithm for these complex systems is which control goals are expected. The whole strategy changes completely depending on whether it is aimed at keeping the engine state at one single level 
or several ones, whether operating-point throttling must be handled, whether transient control should be covered, whether system robustness is a major concern, etc. And generally this global goal is translated first into the choice of an appropriate model capturing the targeted dynamics. LPRE are naturally multivariable systems whose states mainly consist in pressures, temperatures, rotational speeds and mass flows. The state components must satisfy shafts mechanical equations and thermo-fluid-dynamic conservation equations on mass, energy and momentum, which induce high coupling between the variables. These differential equations, originally three-dimensional, can be firstly treated as zerodimensional, as all reviewed authors do, via standard lumped parameters schemes or directly by neglecting spatial contributions within components. The control of partial differential equations, an emerging field, has not been considered for LPRE, due to their high complexity and to the little interest of taking spatial effects into account. The behaviour of most components can be well described via zero-dimensional equations. Only in chambers would those contributions be relevant, but proved rather difficult to account for in the control design. The formal definition of these equations for the inter-connected components in an LPRE naturally leads to a system of nonlinear ODE, unless linear identification techniques [18, 35] are used from the beginning. Another easier modelling alternative is defining equations already in the frequency domain in a linear way [38, 39, 37]. Describing functions have been used in one reference [47]; in fact most authors have linearised their nonlinear models about steady-state points $[29,31,24,40,41,42,43,44,5,26,45]$, which limits representativeness to a narrow region around those points, as explicitly stated by [43] for instance. The only control-oriented nonlinear modelling approaches present in the literature dealt with engine performance simulations [48, 51, 49], state-space analysis [50], OL optimisation [36, 54, 55], neural networks [52, 53] and hybrid models [56]. These nonlinear models are representative in a wider region than linearised ones but imply a higher complexity. Nevertheless, some authors $[41,24]$ affirm that their linearised models are valid in relatively large domains, e.g. variations of \pm 35 bar about the nominal point in [41].

Measured variables in LPRE mainly consist in pressures, TP rotational speeds, valves positions and some not too elevated temperatures. Mass flows are generally only measured in test benches and not in actual flying engines. Hence, mixture-ratio estimators are common practice $[23,53,3]$. The more sensors are installed, the more precise control would be. Nevertheless, the inclusion of further components in an actual engine reduces its reliability, which is vital in space vehicles. In terms of model, most authors consider first-order transfer functions for sensors. Actuators are primarily valves and igniters. The former are deemed as either first-order or second-order systems with saturations and igniters are discrete elements. Anti-windup schemes have been applied to valves in CNES in order to mitigate their saturation. In fact, in expander-cycle LPRE, it is often the case that the controller forces the valves to be fully open to improve response time accounting for the intrinsic expander-cycle-related limitations. In other words, the slower operation dynamics of this type of engines, dictated by the heat exchange produced in the regenerative cooling circuit, limit the response time of the system.

Concerning the analysis of system characteristics, LPRE are naturally stable systems, which to a certain extent simplifies control objectives by removing the need for stabilisation. Even so, some internal natural resonances, mostly related to $\mathrm{TP}$ rotation, may present frequencies that could destabilise the system [2]. Moreover, some engines present non-minimum phase behaviour, which entails initial reverse reactions [41]. Besides, controllability and observability conditions are rarely satisfied at very low operating points, especially during the sequential phase of start-up [23]. Varying mass flows through valves is hardly achievable, and mass-flowmeters (if installed) valid from very small flows to nominal values may become burdensome.

Regarding controller design strategies, the fact that on the whole LPRE stability is naturally satisfied allows to focus on tracking and perturbation-rejection goals. Reference [3] points out that thrust and mixture-ratio control can be achieved in OL if no high accuracy is required, or if off-line optimisation strategies are pertinent $[36,61]$. The majority of references reviewed have closed the loop, which improves robustness and performance at the cost of installing sensors. Most authors have selected conventional PID-based techniques for controlling around a given nominal point. Concretely, PI controllers are the most used option worldwide, present in US-American, European and Japanese engines [18, 9, 63, 57, 58, 23], while CNES have also dealt with PID. In order to use these techniques in this multivariable application, the initial MIMOs are decoupled into SISO subsystems relating controlled variables to actuators, which are commonly two or three dominant valves. This decoupling is sometimes performed via feed-forward. The algorithm in [9], also including feed-forward for adapting to a larger operating domain, is said to achieve control from 21 to $109 \%$ of nominal thrust. Other conventional CL linear approaches con- 
sidered multivariable state feedback [50, 42].

The only reference employing some kind of CL nonlinear techniques [31], factored damage modelling and control into their loop as other NASA reusable-engine works have done [36, 14, 29], which seems convenient for extending engine life. Nonlinear optimisation regarding damage was performed through SQP, while the inner engine loop was still linear. Other works dealt with the robustness problematic, primarily posed by varying parameters, by means of the generalised KHARITONOv theorem [37] or through $H_{\infty}$ techniques [43, 44]. Only two sister papers have concerned a subtype of hybrid techniques (variable-structure sliding modes) [26, 27], but solely applied to combustion phenomena and not to the global LPRE system. One of the most relevant works, [29], combines some hybrid aspects, like switching, with reconfigurable control strategies, in order to accommodate faults of major valves in SSME. The LQG/LTR method is employed in their main controller. Indeed, the interaction of HMS and control, currently still pretty separate, is considered as a major development area by [68], since it would enhance engine robustness and reliability and hence reusability. The recent work of [45] proposes concrete solutions in this direction, applied to an LPRE subsystem. Besides, transient sequences like start-up or shutdown present discrete-events phases which are still performed in OL nowadays. The order of events is generally fixed by engine operation design, but the temporal separation between events is optimised in one reference [20] via LS, according to structural or system characteristics, the environment or the thermodynamic state. The total duration of transients is increased but robustness to different initial conditions is attained.

An efficient way of testing new control algorithms is to build a hardware-in-the-loop test bench, as [60], able to simulate adverse conditions and component faults. When more knowledge on algorithm performance is gained, tests can proceed in actual engine test benches, which then serve to validate the control strategy for future flights.

In order to relate all these different considerations in control design, it seems relevant to summarise and discuss now the complete combinations of design approaches in order to extract the predominant global strategies. Table 1 synthesises this information. In the goals column, whenever control is specified, it refers to the typical thrust and mixture-ratio control. As it can be seen in the table, few combined approaches of modelling and control are present in the literature. This is because many articles do not provide precise information on the model used for deriving the control law, and at the same time the goals of many other articles only concerned modelling. As pointed out before, PID approaches are related to linear (or linearised) submodels, one of them coming from identification [18]. Further repeated strategies consist in the combination of linearised MIMO systems and robust techniques like $H_{\infty}$ [43, 44], which is an effective way of treating model uncertainties from several origins at a concrete thrust level. Another analogy would be between [42] and [53], which perform state feedback on a linearised MIMO system. The rest of combinations are unique in the literature, which hinders the identification of trends. Nonetheless, it can be observed that more complex control techniques, such as nonlinear optimisation, LQG/LTR, or hybrid or robust strategies, are only associated with linear or linearised models. As commented earlier, nonlinear modelling contributions mainly targeted performance simulations, state-space analysis or OL optimisation [36], the latter being one of the most relevant studies reviewed (together with the hybrid reconfigurable [29]). These observed trends are logical in the sense that linear models allow more flexibility in control design at the price of a reduced validity domain. And this is precisely in direct relation to the goal of the study. Most studies have aimed at controlling engines within some pre-defined operating ranges, which matches very well a linearised model. The few articles facing transient control up from off-design pressure values $[18,23,16]$ (until 1993) did not manage to obtain the same level of performance and robustness at all regions with their controllers, which were usually more adapted to the nominal region. Nonlinear models, and perhaps nonlinear control would be more appropriate for these phases. However, during the predefined (normally OL) sequence of discrete events in start-up and shutdown, there are generally controllability and observability issues due to the low mass flow rates, mainly remarked by [23]. That is the reason why continuous control starts after the end of that sequential phase. Further enhancement of the control of these transient phases will be a crucial area of improvement in LPRE control in the upcoming years, as summarised in the next concluding section.

\section{Concluding remarks and future trends}

This article has reviewed the different automatic control methods applied to liquid-propellant rocket engines, whose respective communities have traditionally remained relatively separate. Even though the total number of academic works and accessible industrial developments is relatively low, sufficient information is 
Table 1: Chronological summary of authors' goals and approaches in modelling and control.

\begin{tabular}{|c|c|c|c|}
\hline & \multicolumn{3}{|c|}{ Approaches } \\
\hline References & Goal & Modelling & Control \\
\hline $\begin{array}{llll}\text { Otтo } & \text { AND } & \text { FlaGe } & 1959 \\
{[18]} & & & \\
\end{array}$ & $\begin{array}{l}\text { Transient and steady-state } \\
\text { control of regeneratively- } \\
\text { cooled hydrogen-fluorine } \\
\text { RE }\end{array}$ & $\begin{array}{l}\text { Linear identification } \\
\text { and static equations, } \\
\text { decoupled SISOs }\end{array}$ & PI, transient switches \\
\hline $\begin{array}{l}\text { McDermott et al } 1966 \\
{[40]}\end{array}$ & $\begin{array}{l}\text { Performance of pressure- } \\
\text { fed bipropellant Surveyor }\end{array}$ & Linearised MIMO & - \\
\hline $\begin{array}{l}\text { SeItZ AND SEARLE } 1973 \\
{[16]}\end{array}$ & $\begin{array}{lcc}\text { SSME } & \text { transient } & \text { and } \\
\text { steady-state control } & \end{array}$ & - & CL after events sequence \\
\hline Zноч 1982 [42] & Steady-state control & Linearised MIMO & CL: state feedback \\
\hline ZHANG 1984 [50] & $\begin{array}{l}\text { Pressure-fed cycle state- } \\
\text { space analysis }\end{array}$ & Nonlinear MIMO & CL: state feedback \\
\hline DUYAR et al 1990 [35] & SSME identification & $\begin{array}{l}\text { Linear identification: } \\
\text { RML }\end{array}$ & - \\
\hline $\begin{array}{l}\text { NeMETH et al } 1991 \text { [23], } \\
\text { [30] }\end{array}$ & $\begin{array}{l}\text { SSME transient analysis } \\
\text { and steady-state control }\end{array}$ & - & PI after events sequence \\
\hline Kolcio et al 1994 [51] & $\begin{array}{l}\text { Transient modelling for } \\
\text { monitoring and control } \\
\text { performance }\end{array}$ & Nonlinear MIMO & - \\
\hline ZHENG et al 1995 [26] & $\begin{array}{l}\text { Monopropellant combus- } \\
\text { tion stabilisation }\end{array}$ & $\begin{array}{l}\text { Linearised, unstable, } \\
\text { time-delay combustion } \\
\text { model (lower level of } \\
\text { LPRE system) [46] }\end{array}$ & $\begin{array}{l}\text { Hybrid: variable-structure } \\
\text { sliding modes, robust stabil- } \\
\text { ity conditions in [27] }\end{array}$ \\
\hline $\begin{array}{l}\text { MUSGRAVE et al } 1996 \\
\text { [29] }\end{array}$ & $\begin{array}{l}\text { SSME reconfigurable ICS } \\
\text { with FDI }\end{array}$ & Linearised MIMO LTV & $\begin{array}{l}\text { LQG/LTR and PI based on } \\
\text { [69] with gain scheduling } \\
\text { and mode switching }\end{array}$ \\
\hline $\begin{array}{l}\text { DAI AND RAY } 1996 \text { [36], } \\
\text { [54], [55] }\end{array}$ & $\begin{array}{l}\text { SSME damage-mitigating } \\
\text { throttling control }\end{array}$ & Nonlinear MIMO & OL optimisation \\
\hline $\begin{array}{lll}\text { BERGMANS } & \text { AND } & \text { MYERS } \\
1997[41] & & \end{array}$ & $\begin{array}{l}\text { Modelling and analysis of } \\
\text { air turbo-rocket }\end{array}$ & Linearised SISOs & - \\
\hline LE FUR et al 1997 [43] & $\begin{array}{l}\text { Expander robust steady- } \\
\text { state control }\end{array}$ & Linearised MIMO & Robust: $H_{\infty}$ \\
\hline $\begin{array}{l}\text { IFFLY AND BRIXHE } 1999 \\
{[48]}\end{array}$ & $\begin{array}{ll}\begin{array}{l}\text { Vulcain } \\
\text { model }\end{array} & \text { performance } \\
\end{array}$ & Nonlinear MIMO & - \\
\hline $\begin{array}{l}\text { SAINT-MARD et al } 1999 \\
\text { [49] }\end{array}$ & $\begin{array}{l}\text { Performance of LPRE, ac- } \\
\text { tuators analysis }\end{array}$ & Nonlinear MIMO & - \\
\hline SANTANA et al 2000 [37] & $\begin{array}{l}\text { Modelling and uncertainty } \\
\text { analysis and management }\end{array}$ & $\begin{array}{l}\text { Linear models based on } \\
\text { [38] and [39] }\end{array}$ & $\begin{array}{l}\text { Robust: Kharitonov's theo- } \\
\text { rem }\end{array}$ \\
\hline $\begin{array}{l}\text { KIFORENKO } \\
\text { KHARITONOV } \\
{[61]}\end{array}$ & $\begin{array}{l}\text { Thrust control from } \\
\text { launcher dynamic perspec- } \\
\text { tive (MR constraint) }\end{array}$ & $\begin{array}{l}\text { Linear launcher dy- } \\
\text { namic equations, with } \\
\text { algebraic relations to } \\
\text { engine }\end{array}$ & OL optimisation \\
\hline $\begin{array}{l}\text { SAUDEMONT AND LE Go- } \\
\text { NIDEC } 2000 \text { [44] }\end{array}$ & $\begin{array}{l}\text { Vulcain robust steady-state } \\
\text { control }\end{array}$ & $\begin{array}{l}\text { Linearised } \\
\text { LPV, LFT }\end{array}$ & Robust: $H_{\infty}$ \\
\hline
\end{tabular}




\begin{tabular}{|c|c|c|c|}
\hline & & Approaches & \\
\hline References & Goal & Modelling & Control \\
\hline LORENZO et al 2001 [31] & $\begin{array}{l}\text { SSME LEC with damage } \\
\text { considerations }\end{array}$ & Linearised MIMO & $\begin{array}{l}H_{\infty} \text { and nonlinear SQP op- } \\
\text { timisation }\end{array}$ \\
\hline YANG et al 2001 [52] & $\begin{array}{l}\text { Modelling for real-time } \\
\text { monitoring, diagnosis and } \\
\text { control }\end{array}$ & $\begin{array}{l}\text { Nonlinear feed-forward } \\
\text { neural network }\end{array}$ & - \\
\hline RTO/NATO 2002 [25] & Active combustion control & - & OL: powerful actuator \\
\hline $\begin{array}{ll}\text { NASSIRHARAND } & \text { AND } \\
\text { KARIMI } 2005 \text { [47] } & \end{array}$ & MR steady-state control & Describing functions & Factorisation theory \\
\hline $\begin{array}{lll}\text { SUNAKAWA } & \text { et } & \text { al } 2008 \\
\text { [63] } & & \end{array}$ & $L E-X$ steady-state control & Linear decoupled SISOs & PI \\
\hline LE GoNIDEC 2011 [62] & Steady-state control & Predictive internal model & CL: state feedback \\
\hline Soltani et al 2012 [5] & FDI of Hopper engine & $\begin{array}{l}\text { Linearised: structural } \\
\text { analysis }\end{array}$ & - \\
\hline LE GoNIDEC 2013 [20] & $\begin{array}{l}\text { Transient sequence adap- } \\
\text { tation }\end{array}$ & Hybrid transient model & $\begin{array}{l}\text { Reconfigurable sequences: } \\
\text { LS, fuzzy and predictive } \\
\text { techniques }\end{array}$ \\
\hline KAI et al 2015 [9] & Steady-state tracking & $\begin{array}{l}\text { Non-model-based, de- } \\
\text { coupled SISOs }\end{array}$ & $\begin{array}{l}\text { Feed-forward and feedback } \\
\text { (PI and thresholds). }\end{array}$ \\
\hline $\begin{array}{llll}\text { LE GoNIDEC } & \text { AND } & \text { FAYE } \\
2015 & \text { [58] } & & \end{array}$ & Steady-state control & - & PI, bang-bang \\
\hline KLEIN et al 2017 [57] & $\begin{array}{l}\text { Expander steady-state con- } \\
\text { trol }\end{array}$ & - & $\begin{array}{l}\text { PI, tracking filters, OL in } \\
\text { transient }\end{array}$ \\
\hline LE GONIDEC 2017 [53] & $\begin{array}{l}\text { Steady-state control with } \\
\text { MR estimation }\end{array}$ & $\begin{array}{l}\text { Linearised MIMO, } \\
\text { nonlinear neural net- } \\
\text { work for estimation }\end{array}$ & CL: state feedback \\
\hline $\begin{array}{l}\text { PÉREZ-RocA et al } 2018 \\
\text { [56] }\end{array}$ & $\begin{array}{l}\text { Vulcain (and generic) tran- } \\
\text { sient modelling for control }\end{array}$ & $\begin{array}{l}\text { Nonlinear hybrid } \\
\text { MIMO }\end{array}$ & - \\
\hline SAROTte et al 2018 [45] & $\begin{array}{l}\text { FDI and reconfiguration of } \\
\text { test-bench subsystem }\end{array}$ & Linearised MIMO & Reconfigurable, LQR \\
\hline
\end{tabular}

present in the literature to analyse the state of the art of this complex topic and its areas of improvement. The main control problem in these multivariable systems primarily consists in tracking set-points in combustionchamber pressure and mixture ratio, whose references stem from launcher needs. Control-valves opening angles are adjusted in order to adapt engine's operating point while respecting some constraints. The different aspects in control systems, concerning modelling, sensors and actuators considerations, system analysis and the actual control techniques, have been reviewed and related to one another. From the comparison of the different approaches reviewed, the most common trend identified relies on linearised models about operating points for synthesising steady-state controllers, most of them based on PID techniques. In those cases, initial MIMO systems are considered decoupled into dominant SISO subsystems. Other more complex approaches present in the literature, incorporating some nonlinear, hybrid or robust techniques, enhance certain aspects of performance and robustness. However, no global approaches have been published that consider not only steady-state but also the demanding transient phases at the same level of performance and robustness. There is also a lack of method comparisons on a common benchmark, even simulated. Besides, only narrow throttling domains are feasible.

The potential need for reusable engines presents stronger robustness requirements than expendable ones due to their multi-restart and thrust-modulation capabilities. These demanding requirements arise from the possible endogenous perturbations due to components faults or evolving parameters and from exogenous perturbations related to the more complex mission profiles forced by new launchers.

The classical multivariable control of main-stage LPRE 
had attained a reduced throttling envelope (70\%-120\%) [17]. In the future European Prometheus engine, it is aimed at throttling down to $30 \%$ [8], and current designs by SpaceX [6], Blue Origin [7] and JAXA [9] are claimed to attain $39 \%, 19 \%$ and $40 \%$ respectively. Thus, an enlarged validity domain for reusability has to be conceived. At least, it becomes crucial to maintain tracking and robustness at those low throttle levels, where physical phenomena are more difficult to anticipate. The damaging combustion instabilities, which might be specifically controlled in simple engines (e.g. monopropellant pressure-fed [26, 28]), are more prone to appear in those cases. The management of this problem, apart from involving other design considerations, directly affects the control system. This system will have to ensure that the desired thrust level is robustly achieved. Indeed, one of the main conclusions of this paper is the absence of fully nonlinear or hybrid frameworks, which may permit the control of a wider throttling domain. In this sense, possible solutions could be enhanced nonlinear approaches accounting for transient behaviour, gain-scheduled switched controllers, large off-line optimised-behaviour scheduling, optimal CL control, etc.

Pre-defined sequences (start-up/shutdown), traditionally managed in open loop with low correction margins, could be adapted according to the evolving system, depending on thermal issues, damages or on the mission. In this sense, the control design path proposed by [17] is hybrid control, blending conditional sequences with continuous control of thrust and mixture ratio.

However, as the conclusions in [23] on the control of transients indicate, controllability and observability issues may hinder that task. Transient control started to be plausible once all events had finished. Thus, those authors proposed to modify SSME configuration so as to enable these characteristics during the discrete-event phase. For instance, lines could already be primed prior to start-up, thereby creating certain mass flows relevant for valve control. If more actuators come into play, such as flow-control surfaces in chambers, the emerging field of partial-differential-equation control may become attractive. This way, spatial effects might become controllable. Such multi-disciplinary design choices, considering the control system as a key element in design loops, will definitely help improve LPRE operation in reusability scenarios.

Damage-rate management is one of the main contributions of NASA's SSME-related research [36, 31, 29]; and indeed it could be beneficial for new reusable engines. Estimating or modelling the damage accumulation of the most exposed components in LPRE, like turbopumps, will certainly help to redefine control constraints and thus improve robustness, as shown in their papers. And in the event that such a component fails, reconfiguration strategies, perhaps making use of switching logics and hence some hybrid elements, will be convenient for ensuring the fail-safe operation of the launcher. A full interaction between control and HMS subsystems would become crucial in that case.

All these enhanced control aspects will not be computationally feasible in many cases without more powerful computers on-board. The authors in [44] highlight that the advantages of such a computer would enable a precise throttling and parameter corrections due to perturbations, which would translate into propellant savings. The problem is that it is generally not practical to install it in the launcher, since it complexifies validation tests due to the inclusion of further reliability factors.

Nevertheless, it might be the appropriate time to start deeming these improved control strategies as a real gain in reliability, contributing to robustify reusable rocket engines.

\section{Acknowledgements}

The authors would like to thank ArianeGroup SAS and Centre National d'Etudes Spatiales (CNES) for the funding.

\section{References}

[1] Iannetti A., Model-based fault diagnosis for rocket engines Methodes de diagnostic pour les moteurs de fusee a ergols liquides, Ph.D. Thesis, Universite Paris-Saclay (2016).

[2] Sutton G.P., Biblarz O., Rocket propulsion elements, 7th Edition, Wiley-Interscience publication, John Wiley and Sons, New York, 2001.

[3] Huzel D.K., Huang D.H., Chapter 7: Design of Rocket-Engine Control and Conditon-Monitoring Systems, in: Modern Engineering for Design of Liquid-Propellant Rocket Engines, AIAA Progress in Astronautics and Aeronautics Richard Seebass, 1992, sponsored by Rocketdyne Division of Rockwell International.

[4] Manfletti C., Transient behaviour modelling of liquid rocket engine components, Vol. PhD Thesis 2009 of Berichte aus der Luft- und Raumfahrttechnik, Shaker Verlag, Aachen, 2010, oCLC: 685183465.

[5] Soltani M., Izadi-Zamanabadi R., Wisniewski R., Belau W., Le Gonidec S., Robust Parametric Fault Estimation in A Hopper System, IFAC Proceedings Volumes 45 (13) (2012) 491-498.

[6] SpaceX Corp., Merlin Engines (2015).

[7] Blue Origin, Blue Origin, Our Approach to Technology (2016).

[8] Baiocco P., Bonnal C., Technology demonstration for reusable launchers, Acta Astronautica 120 (2016) 43-58.

[9] Kai T., Niu K., Obase K., Sakai W., Fukuda Y., Hashimoto T., Sato M., Takada S., Kimura T., Naruo Y., Ogawa H., Yagishita T., Ito T., Engine Control System for the Main Engine of the Reusable Sounding Rocket, in: Proceedings of the International Astronautical Congress, IAC, Vol. 10 of IAC-15,C4,3,2,x28758, IAF, Jerusalem, Israel, 2015, pp. 7389-7394, - JAXA and MHI. 
[10] Filatyev A.S., Buzuluk V., Yanova O., Ryabukha N., Petrov A., Advanced aviation technology for reusable launch vehicle improvement, Acta Astronautica 100 (2014) 11-21.

[11] Deneu F., Malassigne M., Le-couls O., Baiocco P., Promising solutions for fully reusable two-stage-to-orbit configurations, Acta Astronautica 56 (8) (2005) 729-736.

[12] PLD Space, News release for ESA's Future Launcher Preparatory Programme project award to PLD Space (2016).

[13] Tatiossian P., Desmariaux J., Garcia M., CALLISTO project - reusable first stage rocket demonstrator, in: 7TH EUROPEAN CONFERENCE FOR AERONAUTICS AND SPACE SCIENCES (EUCASS), Vol. 680, EUCASS Association, Milan, Italy, 2017.

[14] Lorenzo C.F., Merrill W.C., Musgrave J.L., Ray A., Controls Concepts for Next Generation Reusable Rocket Engines, in: American Control Conference, Vol. FP1-4:10, IEEE, Seattle, USA, 1995, pp. 3942-3950, - NASA Lewis Research Center.

[15] Casiano M.J., Hulka J.R., Yang V., Liquid-Propellant Rocket Engine Throttling: A Comprehensive Review, Journal of Propulsion and Power 26 (5) (2010) 897-923.

[16] Seitz P.F., Searle R.F., Space Shuttle Main Engine control system, in: National Aerospace Engineering and Manufacturing Meeting, Los Angeles, USA, 1973, - NASA NTRS.

[17] Le Gonidec S., An overview of connections between scientific automatic topics and their applications in the propulsive systems, in: Journal of Physics: Conference Series: 13th European Workshop on Advanced Control and Diagnosis (ACD 2016), 783/011001, IOP Publishing, Lille, France, 2017.

[18] Otto E.W., Flage R.A., Control of combustion-chamber pressure and oxidant-fuel ratio for a regeneratively cooled hydrogenfluorine rocket engine, Tech. Rep. Technical note D-82, NASA Lewis Research Center, Cleveland, USA (1959).

[19] Bellows J.T., Brewster R.E., Bekir E., OTV liquid rocket engine control and health monitoring, in: 20th AIAA/SAE/ASME Joint Propulsion Conference, Vol. AIAA-84-1286, AIAA, Cincinnati, USA, 1984, - Rockwell International/ Rocketdyne Division.

[20] Le Gonidec S., Method and a device for calculating a starting or stop sequence for an engine, - SNECMA (ArianeGroup), Vernon, France, US8364374B2, United States Patent (2013).

[21] Rocketdyne Propulsion \& Power, Boeing, Space Shuttle Main Engine Orientation, in Space Transportation System Training Data BC98-04, - Boeing, Rocketdyne Propulsion \& Power (1998).

[22] Timnat Y.M., Advanced Chemical Rocket Propulsion, 1st Edition, Academic Press, London, Orlando, 1987.

[23] Nemeth E., Anderson R., Ols J., Olsasky M., Reusable rocket engine intelligent control system framework design, phase 2, Tech. Rep. NASA Contractor Report 187213, Rockwell International, Canoga Park, California (Sep. 1991).

[24] Lorenzo C.F., Musgrave J.L., Overview of rocket engine control, in: AIP Conference Proceedings, Vol. 246, AIP, 1992, pp. 446455, - NASA.

[25] RTO/NATO, Active control of engine dynamics, RTO Educational notes 20, - OCLC: 249585275 (2002)

[26] Zheng F., Cheng M., Gao W.B., Variable structure control of time-delay systems with a simulation study on stabilizing combustion in liquid propellant rocket motors, Automatica 31 (7) (1995) 1031-1037.

[27] Zheng F., Frank P.M., Robust control of uncertain distributed delay systems with application to the stabilization of combustion in rocket motor chambers, Automatica 38 (3) (2002) 487-497.

[28] Wu Y., Zhang H., Hui J., Zhou X., Non-fragile Hinf controller for combustion process in rocket motors, International Journal of Automation and Control 12 (3) (2018) 381-398.

[29] Musgrave J.L., Guo T.H., Wong E., Duyar A., Real-time accom- modation of actuator faults on a reusable rocket engine, IEEE transactions on control systems technology 5 (1) (1996) 100109, - NASA.

[30] Nemeth E., Anderson R., Maram J., Norman A., Merrill W.C., An advanced intelligent control system framework, in: 28th Joint Propulsion Conference and Exhibit, Vol. AIAA92-3162, American Institute of Aeronautics and Astronautics, Nashville, USA, 1992. doi:10.2514/6.1992-3162.

[31] Lorenzo C.F., Ray A., Holmes M.S., Nonlinear control of a reusable rocket engine for life extension, Journal of Propulsion and Power 17 (5) (2001) 998-1004, - NASA.

[32] Lorenzo C.F., Robust rocket engine concept, in: 31st Joint Propulsion Conference and Exhibit, American Institute of Aeronautics and Astronautics, San Diego, USA, 1995. doi:10. 2514/6. 1995-3123.

[33] Lozano-Tovar P.C., Dynamic models for liquid rocket engines with health monitoring application, Master's thesis, Massachusetts Institute of Technology, MIT Boston (1998).

[34] Ordonneau G., Masse J., Albano G., CARINS: Modelling and simulation software for complex industrial processes based on open-source programmes// Un logiciel de modelisation et de simulation pour les procedes industriels complexes fonde sur des logiciels libres, REE: Revue de l'Electricite et de l'Electronique N. 4, - CNES-ONERA.

[35] Duyar A., Ten-Huei G., Merrill W.C., Space shuttle main engine model identification, IEEE Control Systems Magazine 10 (4) (1990) 59-65, - NASA.

[36] Dai X., Ray A., Damage-Mitigating Control of a Reusable Rocket Engine: Part II-Formulation of an Optimal Policy, Journal of Dynamic Systems, Measurement, and Control 118 (3) (1996) 409-415, - NASA.

[37] Santana A., Barbosa F.I., Niwa M., Goes L.C.S., Modeling and Robust Analysis of a Liquid Rocket Engine, in: 36th Joint Propulsion Conference \& Exhibit, Vol. 2000-3160, AIAA, Huntsville, USA, 2000

[38] Santana A., Goes L.C.S., Design and dynamic characteristics of a liquid-propellant thrust chamber (1999).

[39] Santana A., Goes L.C.S., Dynamic modeling and stability analysis of a liquid rocket engine, in: 15th Brazilian Congress of Mechanical Engineering COBEM, Centro Tecnico Aeroespacial, IAE/CTA, Sao Paulo, Brazil, 1999.

[40] McDermott C.E., Breshears R.R., McCafferty J., Dynamic performance of surveyor throttleable rocket engine operating on propellants containing dissolved gas, in: AIAA Third Annual Meeting, Vol. AIAA 66-949, AIAA, Boston, USA, 1966, - Jet Propulsion Laboratory.

[41] Bergmans J.L., Myers R.I., Throttle valves for air turbo-rocket engine control, in: AIAA/ASME/SAE/ASEE Joint Propulsion Conference \& Exhibit, 33rd, Vol. AIAA 97-3188, AIAA, Seattle, USA, 1997, - CFD Research Corporation.

[42] Zhou X., The analysis for regulation-performance of a variable thrust rocket engine control system, Tech. Rep. FTD ID RS T 522-82 ; AD A 117495, USA Foreign Technology Division, China, edited translation (1982).

[43] Le Fur A., Voisin C., Guillard M.H., Verge M.M., Study of control laws of an expander-cycle rocket engine - Etude de lois de commande pour moteur a cycle expander, ArianeGroup internal report, ArianeGroup, ENSAM, LAAM, Vernon, France (1997).

[44] Saudemont R., Le Gonidec S., Study of a robust control law based on H_infinity for the Vulcain rocket engine - Etude d'une commande robuste a base de commande H_infinity pour le moteur Vulcain, ArianeGroup internal report, ArianeGroup, ESTACA, Vernon, France (2000).

[45] Sarotte C., Marzat J., Piet-Lahanier H., Iannetti A., Galeotta M., Ordonneau G., Actuator Fault Tolerant System For Cryo- 
genic Combustion Bench Cooling Circuit, in: 10th IFAC Symposium on Fault Detection, Supervision and Safety for Technical Processes SAFEPROCESS 2018, Vol. 51, Elsevier, Warsaw, Poland, 2018, pp. 592-599, - ONERA/CNES.

[46] Crocco L., Aspects of Combustion Stability in Liquid Propellant Rocket Motors Part I: Fundamentals. Low Frequency Instability With Monopropellants, Journal of the American Rocket Society 21 (6) (1951) 163-178.

[47] Nassirharand A., Karimi H., Mixture ratio control of liquid propellant engines, Aircraft Engineering and Aerospace Technology 77 (3) (2005) 236-242.

[48] Iffly A., Brixhe M., Performance Model of the Vulcain Ariane 5 Main Engine, in: 35th AlAA/ASME/SAE/ASEE Joint Propulsion Conference and Exhibit, Vol. AIAA 99-2472, AIAA, Los Angeles, USA, 1999, - SNECMA (ArianeGroup).

[49] Saint-Mard M., Hendrick P., Promper C., Rocket engines performance evaluation and regulation properties, in: 35th AIAA/ASME/SAE/ASEE Joint Propulsion Conference and Exhibit, Vol. AIAA 99-2326, AIAA, Los Angeles, USA, 1999.

[50] Zhang Y.L., State-space analysis of the dynamic characteristics of a variable thrust liquid propellant rocket engine, Acta Astronautica 11 (7) (1984) 535-541.

[51] Kolcio K., Helmicki A.J., Jaweed S., Propulsion system modelling for condition monitoring and control : Part I, theoretical foundations, in: 30th AIAA/ASME/SAE/ASEE Joint Propulsion Conference, Vol. AIAA 94-3227, AIAA, Indianapolis, USA, 1994

[52] Yang E., Xu Y., Zhang Z., Nonlinear dynamic neural network model for rocket propulsion systems, Tuijin Jishu/Journal of Propulsion Technology 22 (1) (2001) 50-53.

[53] Le Gonidec S., A method of controlling the pressure and a mixture ratio of a rocket engine, and corresponding device, - Safran Aircraft Engines SAS (ArianeGroup), France, FR3039859B1, Institut National de la Propriete Industrielle (France) (2017).

[54] Dai X., Ray A., Damage-Mitigating Control of a Reusable Rocket Engine: Part I-Life Prediction of the Main Thrust Chamber Wall, Journal of Dynamic Systems, Measurement, and Control 118 (3) (1996) 401-408, - NASA.

[55] Wu M.-K., Ray A., Damage-Mitigating Control of Power Systems for Structural Durability and High Performance, Journal of Engineering for Gas Turbines and Power 117 (2) (1995) 307313, - NASA.

[56] Perez-Roca S., Langlois N., Marzat J., Piet-Lahanier H., Galeotta M., Farago F., Le Gonidec S., Derivation and Analysis of a State-Space Model for Transient Control of Liquid-Propellant Rocket Engines, in: 2018 9th International Conference on Mechanical and Aerospace Engineering (ICMAE), 2018, pp. 5867.

[57] Klein M., Hayoun D., Le Gonidec S., Reichstadt S., Method and a circuit for regulating a rocket engine, - SNECMA (ArianeGroup), Issy-les-Moulineaux, France, US 2017/0101963 A1, United States Patent Application Publication (2017).

[58] Le Gonidec S., Faye O., Device for adjusting an operating variable of an engine, - SNECMA (ArianeGroup), France, US9037380B2, United States Patent (2015).

[59] Chopinet J-N., Lassoudiere F., Roz G., Faye O., Le Gonidec S., Alliot P., Guedron S., Pinhede H., Progress of the development of an all-electric control system of a rocket engine, in: 48th AIAA/ASME/SAE/ASEE Joint Propulsion Conference \& Exhibit, Vol. AIAA 2012-3873, American Institute of Aeronautics and Astronautics, Atlanta, USA, 2012. doi:10.2514/6. 2012-3873.

[60] Romet A., Cliquet Moreno E., Espinosa Ramos A., Dreyer S., Stillace T., Godi M., Bruneau Q., Tatiossian P., Jues T., Le Gonidec S., A flexible real-time simulation platform dedicated to embedded rocket engine control systems development and testing, in: 7th European Conference for Aeronautics and Space Sciences (EUCASS), Vol. 162, EUCASS Association, Milan, Italy, 2017.

[61] Kiforenko B.N., Kharitonov A.M., Control of Thrust of Liquid Rocket Engines: Simulation and Optimization, Journal of Automation and Information Sciences 32 (8) (2000) 47-63.

[62] Le Gonidec S., Device for controlling a regulated system, and an engine including such a device, - Safran Aircraft Engines SAS, France, US8005554B2, United States Patent (2011).

[63] Sunakawa H., Kurosu A., Okita K., Sakai W., Maeda S., Ogawara A., Automatic Thrust and Mixture Ratio Control of the LE-X, in: 44th AIAA/ASME/SAE/ASEE Joint Propulsion Conference \& Exhibit, Vol. 2008-4666, AIAA, Hartford, USA, 2008, - JAXA and MHI.

[64] Bars R., Colaneri P., de Souza C.E., Dugard L., Allgoewer F., Kleimenov A., Scherer C., Theory, algorithms and technology in the design of control systems, Annual Reviews in Control 30 (1) (2006) 19-30.

[65] Bhattacharyya S.P., Chapellat H., Keel L.H., Robust Control: The Parametric Approach, 1st Edition, Prentice Hall PTR, Upper Saddle River, NJ, USA, 1995.

[66] Zhang Y., Jiang J., Bibliographical review on reconfigurable fault-tolerant control systems, Annual Reviews in Control 32 (2) (2008) 229-252.

[67] Wu J., Liquid-propellant rocket engines health-monitoring - a survey, Acta Astronautica 56 (3) (2005) 347-356.

[68] Marcos A., Penin L., Le Gonidec S., Lemaitre A., HMSControl-Interaction architecture for rocket engines, in: AIAA Guidance, Navigation, and Control Conference, Vol. AIAA 2012-4679, American Institute of Aeronautics and Astronautics, Minneapolis, USA, 2012. doi:10.2514/6.2012-4679.

[69] Musgrave J.L., Linear quadratic servo control of a reusable rocket engine, Journal of Guidance, Control and Dynamics 15 (5) (1992) 1149-1154, - NASA. 